Ebisu Ebisu

Études japonaises Études japonaises

$51 \mid 2014$

Le rapprochement franco-japonais dans l'entre-deuxguerres

\title{
Le développement de la japonologie en France dans les années 1920 : autour de la revue Japon et Extrême-Orient
}

杂隹誌『日本と極東』と1920年代のフランスにおける日本学の発展

The Development of Japanese Studies in 1920s France: Focus on the Journal

Japon et Extrême-Orient

\section{Christophe Marquet}

\section{(2) OpenEdition}

Journals

Édition électronique

URL : http://journals.openedition.org/ebisu/1388

DOI : 10.4000/ebisu. 1388

ISSN : 2189-1893

Éditeur :

Institut français de recherche sur le Japon (UMIFRE 19 MAEE-CNRS), Maison franco-japonaise

Édition imprimée

Pagination : 35-74

ISSN : 1340-3656

Référence électronique

Christophe Marquet, «Le développement de la japonologie en France dans les années 1920 : autour de la revue Japon et Extrême-Orient », Ebisu [En ligne], 51 | 2014, mis en ligne le 01 novembre 2014, consulté le 02 mai 2019. URL : http://journals.openedition.org/ebisu/1388 ; DOI : 10.4000/ebisu.1388 


\section{Le développement de la japonologie en France dans les années 1920 : autour} de la revue Japon et Extrême-Orient Christophe Marquet

雑誌『日本と極東』と

1920 年代のフランスにおける日本学の発展

クリストフ・マルケ

The Development of Japanese Studies

in 1920s France: Focus on the Journal

Japon et Extrême-Orient

Christophe MarqueT

\ots-clés : japonologie, littérature japonaise, École française d'Extrême-Orient, Japon et ExtrêmeOrient (périodique), Serge Elisséev, Claude Eugène Maitre, Moïse Charles Haguenauer.

L'auteur : Christophe Marquet, historien de l'art, est professeur à l'Institut national des langues et civilisations orientales (Inalco, Paris) et directeur de l'UMIFRE 19 (Maison franco-japonaise) et de l'USR 3331 " Asie orientale " du CNRS.

Résumé : La Première Guerre mondiale est marquée en France par le déclin du japonisme esthétique et par un nouvel intérêt pour le Japon contemporain. En 1923, une publication périodique, Japon et Extrême-Orient, éditée par Claude Eugène Maitre (1876-1925), ancien directeur de l'École française d'ExtrêmeOrient, se proposa d'apporter au public français "des éléments d'information et d'appréciation aussi nombreux et aussi précis que possible sur un pays vers lequel le porte une sympathie spontanée, mais insuffisamment avertie [...]». Cette éphémère revue aux sujets éclectiques donne une idée de l'état des études japonaises au début des années 1920 et du niveau d'information sur ce pays en France à cette époque. Les pionniers de la japonologie, comme Serge Elisséev ou Moïse Charles Haguenauer, y apportèrent leur contribution à une meilleure connaissance du Japon moderne et contemporain en vue d'un rapprochement intellectuel entre les deux pays. 
キキーワード 日本学、日本文学、フラン ス極東学院、雑誌『日本と極東』、セルジュ・ エリセーエフ、クロード = ウジェーヌ・メート ル、モイーズ=シャルル・アグノエル

\section{著者}

日本美術史専門、フランス国立東洋言語文化 大学（イナルコ）日本語・日本文化学科教授、 日仏会館フランス事務所所長、フランス国立 科学研究センター「東アジア」研究ユニット ディレクター。

\section{要旨}

第一次世界大戦後のフランスにおける日本へ の関心は、芸術的なジャポニズムよりもむし ろ現代日本の社会へと向けられるようになっ た。1923年 12 月に『日本と極東』(Japon et Extrême-Orient) という月刊誌がフランス 極東学院の元学長でもあったクロード=ウ ジェーヌ・メートル $(1876$ - 1925) によっ て創刊され、日本の政治、経済、芸術、文学 についての情報を網羅しようとした。この雑 誌はフランスで「日本びいきであっても充分 な情報が得られなかった当時の人々のために できるかぎり豊富で正確な情報や論評を」提 供することを目的とした。短期間のうちに廃 刊になったが、日本についての様々な情報を 揭載したことにより 1920 年代初めのフラン スの日本学の状況や日本に対する認識を知る 重要な手がかりとなるものである。セルジュ・ エリセーエフやルイ・オーベール、モイーズ =シャルル・アグノエルなどの日本学の先駆 者が日仏の知的交流という観点で当時の日本 への知識を深めることに貢献したといえよう。

\section{\ Keywords:}

Japanese Studies, Japanese Literature, École française d'Extrême-Orient, Japon et Extrême-Orient (Journal), Serge Elisséev, Claude Eugène Maitre, Moïse Charles Haguenauer

The Author: Christophe Marquet, a specialist in art history, is a professor at the Institut national des langues et civilisations orientales (Inalco, Paris). He heads the research unities UMIFRE 19 (Maison franco-japonaise) and USR 3331 "East Asia” at the CNRS.

Abstract: In France, World War I signalled both the decline of Japonism in the arts and a new interest in contemporary
Japan. In 1923, Claude Eugène Maitre (1876-1925), former head of the École française d'Extrême-Orient, launched the journal Japon et Extrême-Orient to provide French readers with "as much and as far as possible precise information on a country to which they are naturally drawn but know little about [...]". Though short-lived, this eclectic journal gives an idea of the state of Japanese Studies in the early 1920s and the level of information on Japan available in France at the time. Through the journal, pioneering Japanologists like Serge Elisséev and Moïse Charles Haguenauer spread knowledge of modern and contemporary Japan in order to encourage intellectual exchange between the two countries. 


\section{Le développement de la japonologie en France dans les années 1920 Autour de la revue Japon et Extrême-Orient}

Christophe MARQUET*

\section{Les premières revues de langue française consacrées au Japon}

Les revues constituent une source de première main particulièrement précieuse pour mener une recherche sur l'état de la connaissance du Japon en France dans l'entre-deux-guerres, période où la vie intellectuelle, artistique, littéraire ou politique était largement relayée par ce type de média. Nous nous intéresserons ici au milieu des années 1920, moment de la création de la Maison franco-japonaise, et principalement à un périodique : Japon et Extrême-Orient. Revue d'informations politiques, économiques, artistiques et littéraires. Cette revue, qui ne connut que douze numéros (en dix livraisons) entre décembre 1923 et décembre 1924, reste en effet relativement mal connue, malgré sa remarquable qualité et la nature particulièrement ambitieuse de son projet éditorial' ${ }^{1}$.

* MFJ UMIFRE 19 (MAEDI/CNRS).

1. La revue Japon et Extrême-Orient est conservée partiellement dans onze bibliothèques universitaires japonaises, mais seule celle de l'Institute for Advanced Studies on Asia de l'université de Tokyo (Tōkyō daigaku Tōyō bunka kenkyūjo toshoshitsu 東京大学東洋文化研究所図書室) en possède la collection complète. La bibliothèque de la Maison franco-japonaise a fait récemment l'acquisition des douze numéros, à l'occasion du colloque sur « Le rapprochement franco-japonais dans l'entre-deux-guerres » qui s'est tenu dans ses locaux les 5 et 6 octobre 2013. En France, la Bibliothèque nationale de 
Rappelons tout d'abord en guise d'introduction ce que furent, depuis la fin du XIX ${ }^{e}$ siècle, les premiers périodiques de langue française consacrés au Japon. Ils sont essentiellement au nombre de trois. Le premier est la Revue française du Japon (dont le titre japonais est Futsubun zasshi 佛文雜誌) (fig. 1), fondée par le juriste Gustave Émile Boissonade de Fontarabie (1825-1910), conseiller légal du gouvernement japonais et rédacteur du code pénal. Cette revue mensuelle fut publiée pendant six années, de 1892 à 1897 ( $1^{\text {re }}$ série 36 numéros, $2^{\mathrm{e}}$ série 20 numéros, $3^{\mathrm{e}}$ série 6 numéros), sous le patronage de la Société de langue française (Futsugaku-kai 佛學會) créée par des universitaires francophones comme Furuichi Kōi 古市公威 (1854-1934), ancien élève de l'École centrale de Paris, qui deviendra à la fin de sa vie président de la Maison franco-japonaise. La publication avait son siège à l'École de droit franco-japonaise (Wafutsu hōritsu gakkō 和佛法律學校) fondée en 1889 et dirigée par Boissonade, la future université Hōsei ${ }^{2}$ Parmi ses collaborateurs importants figurent le collectionneur japonisant Emmanuel Tronquois et Maurice Courant, interprète de la Légation de France à Tokyo de 1893 à 1895 et qui sera membre de la mission universitaire confiée en 1919 par le ministère de l'Instruction publique au recteur de l'académie de Lyon Paul Joubin, en vue de la création d'un « institut français » au Japon (la future Maison franco-japonaise) ${ }^{3}$. On note également les contributions de Joseph Dautremer (interprète à la Légation de France à Tokyo depuis 1880, futur titulaire de la chaire de japonais de l'École des langues orientales vivantes à partir de 1911) ou encore de Noël Peri (1865-1922), prêtre de la Société des missions étrangères de Paris et l'un des pères de la japonologie française, à qui l'on doit notamment les premières traductions de pièces de nô en français ${ }^{4}$.

France et la bibliothèque du musée Guimet en possèdent la collection complète. Cette publication a été dépouillée par Patrick Beillevaire (1993), de même que les trois autres revues citées ensuite. Bernard Frank cita la revue avec enthousiasme dans sa communication sur " La japonologie, histoire et définition d'une approche ", en ouverture du colloque "Le Japon vu depuis la France. Les études japonaises en France » (Frank 1981 : 14). Une des rares études qui aborde cette revue est un texte sur le musée Guimet et la culture japonaise (Hasegawa-Sockeel 2012).

2. Sur cette revue, voir Iwatani 1999 ; Shiratori 1999 ; Marquet 2002 : 129-133. Un fac-similé est disponible (RFJ 2007).

3. Sur Maurice Courant et la mission Joubin, voir Bouchez 1983.

4. Un hommage lui sera rendu par Claude Maitre dans Japon et Extrême-Orient en 1924 (Maitre 1924). Voir aussi Noël Peri, Cinq Nô : drames lyriques japonais (Peri 1921). 


\section{佛 文雜誌}

\section{REVUE FRANÇAISE}

\section{DU JAPON}

PUBLIÉE SOUS LE PATRONAGE

DE LA SOCIÉTÉ DE LANGUE FRANC,AISE.

PREMIL̀RE ANNÉE

$$
\text { I } 892 .
$$

AU WA-FUTSU HoRITSU GaKKo, No. 16, 6e-Rue, Fujimi-cho, Kojimachi-ku.

Tokno.

Fig. 1

Revue française du Japon /

Futsubun zasshi 佛文雜誌,

$n^{\circ} 1,1892$. Bibliothèque de

la Maison franco-japonaise. 


\section{MELANGES}

Première Année. NO 1. Janvier 1904.

\section{EXTRAIT'S DES REVUES ET JOURNAUX JAPONAIS}

\section{La religion de l'avenir}

Ukita Wamin.

(Rikugò Zersshi, nevue whitairiente, No. 174.)

Jadis on attribuait une autorité absolue (zettaiteki ken-i) aux fondateurs de religion et aux livres sacrés renfermant leur doctrine. Mais la haute critique $(k \bar{s} t \bar{o} \operatorname{l} l \not h y \bar{o})$ a fait justice de ces prétentions qui sont désormais devenues insoutenables. Actuellement, les religions sont sorties de l'isolement ou leurs fidèles respectifs pouvaient sans contradiction les exalter à qui mieux mieux, les Chrétiens fa'sant du Christ un Dieu ou le Fils de Dieu, les. Bouddhistes faisant de Shaka le Bouddha ou la personnification du Bouddha. Dans le plein jour où sont maintenant exposées les religions du monde, chacune apparait avec son fort et son faible. Or, d'après le commun des philosophes, le soin de distinguer le vrai et le faux, le fort et le faible des religions appartient à la raison (risei.) La raison, jouissant de l'autorité absolue dont a été dépossédée la religion, doit juger de tout en dernier ressort et sans appel. Mais de nos jours la théorie du transformisme (slinkworron) a fait tomber cette prétention. Car, d'après le transformisme, la raison, tirant son origine de l'évolution d'un cerveau d'animal inférieur, suivant les lois de la concurrence vitale (seison $k y \bar{j} s \overline{0})$, n'est plus, comme on a pu le croire, cette faculté innée (sententeki nóryoku) dont l'autorité est absolue. Peut-être l'homme,

\section{Fig. 2}

Mélanges, n 1, janvier 1904.

Bibliothèque de la Maison

franco-japonaise. 
Cette revue, rédigée en partie par cette première génération de japonisants français en poste au Japon, avait pour vocation de promouvoir la langue française dans les milieux intellectuels et universitaires japonais et de fournir des informations précises sur le Japon. Elle abordait une large palette de sujets (à l'exception des questions strictement politiques) portant sur l'actualité, le droit, mais aussi l'histoire et la culture. Elle publia également des statistiques officielles, quelques traductions de textes littéraires, des chroniques et rapportait des jugements.

La seconde publication périodique sur le Japon en langue française est la revue trimestrielle Mélanges (devenue en 1906 Mélanges japonais) (fig. 2), publiée de janvier 1904 à octobre 1910 (28 numéros) par Sansaisha 三才 社, la toute première librairie française du Japon, créée en 1898 à Tokyo par Noël Peri. Ce dernier fut l'un des principaux collaborateurs de cette publication avec plusieurs de ses confrères des Missions étrangères, comme les pères Claude Lemoine, Edmond Papinot, Étienne Léon Ballet, Michel Steichen ou Gustave Cesselin, dont les contributions aux études japonaises sont bien connues (Maitre 1922 : 409-412).

Ces deux premières revues furent éditées à Tokyo, entièrement en français - la première cherchant en particulier à contribuer au développement de cette langue au Japon, la seconde à éclairer le travail des missionnaires et on peut penser que leur diffusion resta de ce fait assez confidentielle, aussi bien au Japon qu'en France. Elles méritent néanmoins, par la qualité de leur contenu, d'être évoquées ici comme les premières tentatives de fournir aux lecteurs francophones des informations exactes et précises sur la politique, la société, la littérature ou l'histoire du Japon, en même temps que sur l'actualité ou les statistiques officielles. La seconde revue, Mélanges, se proposait de présenter en français, tout d'abord à l'attention des missionnaires, des traductions d'informations et d'opinions tirées de la presse et des revues académiques et intellectuelles japonaises, afin de faire connaître le savoir japonais, dans le champ principalement religieux, moral et philosophique, mais aussi scientifique ou de l'économie politique et de "donner ainsi une idée suffisamment claire de ce que pensent et disent les Japonais ${ }^{5}$ ", d'après des sources de première main.

5. "À nos lecteurs ", Mélanges, première année, n 1, janvier 1904. 
Une troisième revue, qui parut elle à Paris de 1902 à 1932 (74 numéros), est le Bulletin de la Société franco-japonaise de Paris (fig. 3). Cette publication visait essentiellement à éditer les conférences et à relayer les informations sur la vie de cette société savante et mondaine, connue en japonais sous le nom de Nichifutsu kyōkai 日佛協會, fondée le 16 septembre 1900 au moment de l'Exposition universelle. Cette société réunissait des diplomates japonais en poste en France, des amateurs d'art japonais, des hommes d'affaires, des universitaires et des personnalités du milieu culturel. Elle avait à ses débuts une orientation surtout artistique, dans le prolongement du japonisme. Sa présidence fut initialement assurée par l'ingénieur Louis-Émile Bertin (qui contribua au développement de la Marine japonaise), la vice-présidence par Émile Guimet, Édouard Mène (médecin et collectionneur d'armes et d'armures japonaises), le galeriste Siegfried Bing et le collectionneur d'art japonais Raymond Koechlin, et le secrétariat par le peintre Félix Régamey (qui avait accompagné Guimet lors de sa mission au Japon en 1876). Elle comptait environ 190 membres en $1905^{6}$ et près de 350 en $1928^{7}$. Le japonologue Claude Eugène Maitre (1876-1925), dont il va être question ici, en devient le secrétaire général le 17 mars 1925, quelques mois avant de disparaître.

\section{Le projet de la revue Japon et Extrême-Orient}

On peut donc considérer que la revue Japon et Extrême-Orient fut le premier périodique en langue française exclusivement consacré au Japon à être édité sur le territoire métropolitain, avec une diffusion large et une ambition plus généraliste que les trois précédents, qui étaient avant tout des organes de sociétés savantes ou de congrégations. La publication d'une telle revue, à un rythme mensuel, était un pari très ambitieux, qui montre aussi que le Japon devint après la Première Guerre mondiale l'objet d'une attention nouvelle en France.

6. "Liste alphabétique des membres de la Société franco-japonaise de Paris », Bulletin de la Société franco-japonaise de Paris, $\mathrm{n}^{\circ} 3$, juin 1905, p. 9-14.

7. "Liste alphabétique des membres de la Société franco-japonaise de Paris à la date du 31 décembre 1928 ", Bulletin de la Société franco-japonaise de Paris, nº 69, 1928, p. 11-18. 


\section{I-I 902}

\section{BULLETIN}

DE LA

\section{Société Franco-Japonaise de Paris}

Fondée le 16 Septembre 1900

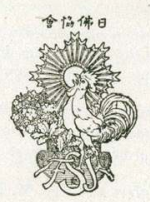

SIÉGE SOCIAL

45, Rue de GRenelle (VIr ${ }^{e} \mathrm{Arr}^{\mathrm{t}}$ )

PARIS

\section{Fig. 3}

Bulletin de la Société franco-

japonaise de Paris, $\mathrm{n}^{\circ} 1,1902$.

Bibliothèque de la Maison

franco-japonaise. 
L'idée de cette publication est due à Serge Elisséev (1889-1975), jeune et brillant japonologue qui s'était installé en France en février 1921 avec sa famille, fuyant la Russie bolchévique. À son arrivée à Paris, il avait rédigé directement en japonais pour le journal Asahi d'Osaka, le poignant témoignage de cette période difficile et de son emprisonnement, sous le titre Sekiro no hitojichi nikki 赤露の人質日記 (Journal d'un otage de la Russie rouge $)^{8}$ (fig. 4). Elisséev travaillait alors comme interprète à l'ambassade du Japon, tout en aidant bénévolement au classement des collections japonaises du musée Guimet et en assurant des enseignements sur l'histoire de la littérature d'Edo en Sorbonne et sur la grammaire japonaise classique à l'École des langues orientales vivantes9. Au cours de trois séjours au Japon entre 1908 et 1917, il avait étudié la littérature, la linguistique et l'art japonais à l'université impériale de Tokyo auprès des meilleurs spécialistes de son temps, qui avaient posé les bases de ces disciplines ${ }^{10}$. Il avait aussi fréquenté dans les mêmes années le milieu des écrivains et du théâtre de la capitale japonaise, ce qui faisait de lui à cette époque à Paris l'un des meilleurs connaisseurs du Japon et de sa culture. Il venait de publier en 1923 un remarquable ouvrage d'introduction à l'art depuis Meiji, La peinture contemporaine au Japon ${ }^{11}$, pour accompagner la toute première exposition d'artistes modernes japonais en France, qui

8. Le texte fut publié dans l'Ōsaka Asahi shinbun entre juillet et octobre 1921, puis repris en volume par les éditions de ce journal (Elisséev 1921).

9. On trouvera sa biographie détaillée dans Reischauer 1957 ; David 1976 ; Kurata 2007 et Beillevaire 2012.

10. Elisséev avait fait trois séjours au Japon : le premier dura six ans, de septembre 1908 à l'été 1914, de l'âge de 19 à 25 ans. Il avait suivi notamment à l'université impériale de Tokyo les cours du linguiste Ueda Kazutoshi 上田萬年, des historiens de la littérature Haga Yaichi 芳賀矢一 et Fujioka Sakutarō 藤岡作太郎, de l'historien Mikami Sanji 三上参次 et de l'historien de l'art Taki Seiichi 澈精一. Son mémoire de fin d'études en 1912 portait sur Bashō. En 1916, il fut accepté en doctorat et fit un deuxième séjour au Japon pendant l'été pour en commencer la préparation. Il fit un troisième séjour pendant l'été 1917.

11. Les deux premiers chapitres, intitulés «Aperçu historique de l'évolution de la peinture japonaise » et "La peinture au début des années de l'époque Meiji (1868-1900)» sont principalement fondés sur l'ouvrage de Fujioka Sakutarō, Kinsei kaiga-shi 近世繪畫 史 (Histoire de la peinture moderne, Tokyo, Kinkōdō 金港堂, 1903), dont Elisséev avait suivi les enseignements à l'université de Tokyo, et qui constitua la première synthèse rédigée au Japon sur la peinture depuis l'époque d'Edo. 


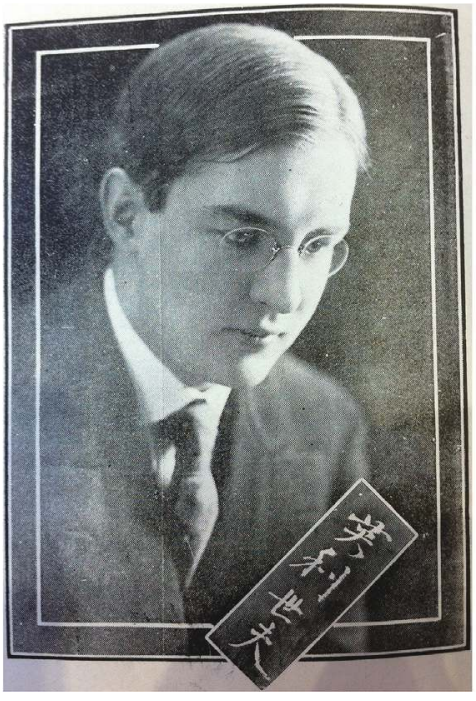

Fig. 4

Serge Elisséev, d'après Sekiro no hitojichi nikki (Elisséev 1921).

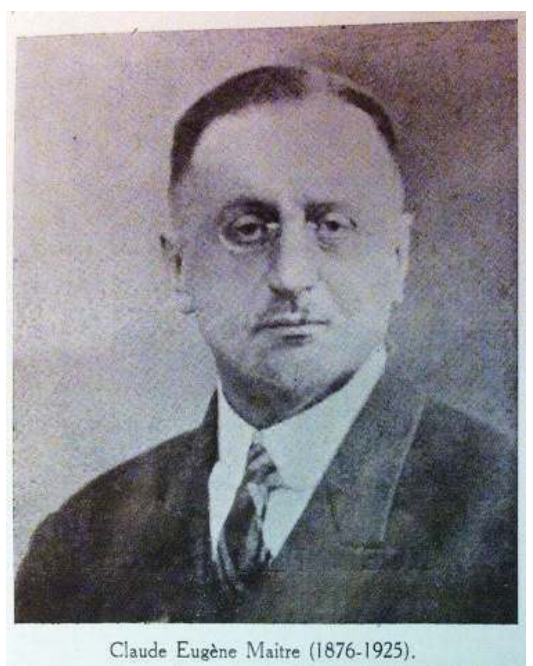

Fig. 5

Claude Eugène Maitre, d'après Extrême-Asie. Revue indochinoise illustrée, $\mathrm{n}^{\circ} 40$, octobre 1929.

s'était tenue l'année précédente au Grand Palais dans le cadre du Salon de la Société nationale des beaux-arts (Elisséev 1923).

C'est Elisséev, en réponse semble-t-il à une demande de l'ambassade du Japon à Paris (Reischauer 1957 : 22), qui suggéra pendant l'été 1923 l'idée de créer une revue culturelle consacrée au Japon, en s'adressant à Claude Maitre (fig. 5), ancien directeur de l'École française d'Extrême-Orient, devenu depuis peu conservateur adjoint (c'est-à-dire sous-directeur) du musée Guimet qui fut l'un des pères de la japonologie française au début du $\mathrm{Xx}^{\mathrm{e}}$ siècle $^{12}$.

12. Elisséev et Maitre se connaissaient depuis octobre 1921. 
"Au mois d'août 1923, je soumis à Maitre la proposition de publier une revue consacrée à l'Extrême-Orient. II acquiesça avec plaisir à ce projet, devint directeur de ce périodique et accepta de rédiger, pour chaque numéro, une chronique sur le Japon. À la fin de l'année 1923, paraît le premier numéro de la revue mensuelle Japon et Extrême-Orient. »(Elisséev 1927a : 56)

Normalien, sorti major de l'agrégation de philosophie en 1898, Maitre avait découvert le Japon la même année grâce à une bourse de voyage "Autour du monde " de l'université de Paris, financée par le mécène Albert Kahn. Il fut recruté en 1901 par l'École française d'ExtrêmeOrient, envoyé à Hanoi comme pensionnaire, puis professeur de japonais à partir de 1905, et nommé rapidement directeur de la jeune institution (1908-1920). «Il arrivait en Indochine, écrit Paul Pelliot, avec l'ambition de créer enfin cette école française de japonologie que Léon de Rosny, pendant quarante ans, avait empêchée de naître " (Pelliot 1925-1926 : 294). Maitre acquit au cours d'un séjour de plus de dix ans en Indochine, entrecoupé de missions longues au Japon (1902, 1903, 1904, 19051906, 1909), une remarquable expertise sur ce pays et des connaissances approfondies en matière d'art, d'histoire et de littérature japonaises classiques $^{13}$. Mobilisé en France en 1916, il s'était lancé un temps dans les affaires après la guerre, avant de revenir à son travail de chercheur grâce à sa nomination au musée Guimet. Les nombreux et précis comptes rendus de la littérature savante sur le Japon qu'il publie dès ses premières années de contact avec ce pays dans le Bulletin de l'École française d'ExtrêmeOrient dévoilent son érudition et la justesse de son jugement. Il formule à l'inverse des critiques sévères à l'encontre des récits de voyage de l'écrivain André Bellessort (Maitre 1903) ou des ouvrages de grammaire de Rosny (Maitre 1903, Maitre 1904). La bibliothèque du musée Guimet conserve une partie de sa bibliothèque d'étude (composée d'environ 330 titres japonais d'ouvrages et de collections de référence en langue, littérature, histoire, géographie, art ou religion, publiés essentiellement dans les années 1888-1923, et d'environ 200 ouvrages en langues occidentales sur

13. Sur le parcours et l'œuvre de Maitre, voir Pelliot 1925-1926 ; Aurousseau 1925 ; Goloubew 1929 ; Beillevaire 2012. 
le Japon $)^{14}$, qui donne une idée de l'ampleur et de la qualité de sa documentation de première main. La même bibliothèque possède également de nombreux manuscrits inédits de travaux de Maitre sur le Japon (notes de terrain, transcriptions d'inscriptions et de documents, traductions et analyses de textes académiques), qui révèlent la variété de ses connaissances et de ses centres d'intérêts sur le Japon ${ }^{15}$. Les notes d'une conférence sur l'" Iconographie bouddhique japonaise du VII ${ }^{\mathrm{e}}$ au XI ${ }^{\mathrm{e}}$ siècle ${ }^{16}$, donnée au musée Guimet le 8 mai 1921, montrent comment il entendait se dégager d'un japonisme encore vivace à Paris à l'époque, qui avait selon lui réduit l'art japonais à ses "bibelots " et à ses productions des périodes les plus récentes, méconnaissant ses « formes les plus hautes » dans l'architecture, la sculpture et la peinture.

C'est donc cet érudit japonisant de haut niveau qui prit la direction de cette revue dont le premier numéro parut le $1^{\text {er }}$ décembre 1923, chez l'éditeur Edmond Bernard ${ }^{17}$, sous le titre Japon et Extrême-Orient. Revue d'informations politiques, économiques, artistiques et littéraires (fig. 6). Le comité de rédaction - qui était aussi le noyau dur des contributeurs de la revue - était composé d'un secrétaire, Lucien Bec, normalien et auteur d'articles sur la

14. Nous tenons à remercier la directrice de la bibliothèque du musée Guimet, Mme Cristina Cramerotti, ainsi que la conservatrice en charge des collections japonaises, Mme Masako Hasegawa-Sockeel, de nous avoir permis l'accès à ce fonds Claude Maitre, donné en son temps par sa famille et qui fut classé par S. Elisséev. Par ailleurs, la bibliothèque de l'EFEO à Hanoi comportait au début des années 1920 un fonds japonais relativement riche, constitué par Maitre et Peri : " Le fonds japonais de la bibliothèque comprend actuellement, d'une part 805 ouvrages en 2682 volumes brochés ou reliés à l'européenne (cote J), de l'autre 533 ouvrages en 3909 fascicules brochés à la japonaise (cote N), soit en tout 1338 ouvrages. " (BEFEO 1921b : 395). Les éditions de l'époque d'Edo et les livres et revues de Meiji les plus importants conservées dans ce fonds sont décrits p. 396-397.

15. La partie de ce fonds qui concerne le Japon est composée de 44 dossiers (y compris quelques manuscrits d'articles publiés dans Japon et Extrême-Orient et quelques textes de Peri) et forme un ensemble considérable de notes et de textes qui témoignent de l'ampleur des recherches menées par Maitre sur l'épigraphie, l'histoire, la littérature et l'art du Japon ancien (en particulier la période de Nara).

16. Bibliothèque du musée Guimet, fonds C. E. Maitre, $\mathrm{n}^{\circ} 20$.

17. Cet éditeur avait notamment publié en 1921 les conférences données au Collège de France par l'historien des religions Anezaki Masaharu : Quelques pages de l'histoire religieuse du Japon, dans la collection des "Annales du musée Guimet ». 


\section{JAPON ET EXTRÊME-0RIENT}

\section{Revue Mensuelle}

Notre Programme.

SOM MA IRE

EUGÈNE VERGNAUD, - Japon et Russie, $I$.

SHIGA NAOYA. - Le Crime du Jongleur (Trad. par Serge ELISSÉEV).

CLAUDE MAITRE. - Nocturnes japonais.

Notre Hors-Texte: Une scène de l'lse monogatari.

Documents : Le mouvement de la population japonaise en 1922.

Chronique: Le ministère Yamamoto. - La catastrophe du $1^{\text {*x }}$ septembre. - Après les accords de Washington. - Le Japon et le Proche-Orient. - In peintre japonais : Ishii Hakutel. - L'extraction du cuivre au Japon. - L'industrie des produits tinctoriaux au Japon. - "L'unique espoir de la Chine 1 . - Notes économiques.

Bibliographie : Un nouveau livre sur le théâtre japonais. - Une conférence de M. Paul Claudel.

\section{HORS-TEXTE}

Un paravent de Kôrin.

\section{EDMOND BERNARD, Éditeur.}

47, rue Miromesnil, 47

PARIS - VIII

Fig. 6

Japon et Extrême-Orient, $n^{\circ} 1,1^{\text {er }}$ décembre 1923.

Bibliothèque de la Maison franco-japonaise. 
géopolitique en $A s i e^{18}$, et de cinq membres : outre les deux japonologues Elisséev et Maitre, le poète Paul-Louis Couchoud (1879-1959), normalien lui aussi, philosophe et médecin, qui avait visité le Japon au moment de la guerre russo-japonaise, également grâce à une bourse Albert Kahn ${ }^{19}$, y faisant la connaissance de Maitre, puis qui y était retourné pour un second séjour en 1912. On lui doit l'introduction du haïkaï, dans son livre Sages et poètes d'Asie (1916), qui exerça une influence décisive sur le mouvement du haïkaï français dans les années $1920^{20}$.

Figuraient également dans ce comité le commandant Raymond Martinie (1870-1958) ${ }^{21}$, ancien attaché naval de l'ambassade de France au Japon et premier traducteur de Natsume Sōseki 夏目漱石, mais aussi connaisseur des questions économiques et financières, et Louis Aubert (1876-1965), normalien, agrégé de lettres et auteur avant la Première Guerre mondiale de plusieurs ouvrages sur le Japon et les relations internationales, l'immigration

18. Lucien Bec rédigera par exemple une note sur "Quelques aspects du conflit américano-japonais " (Revue universelle, $1^{\text {er }}$ septembre 1924, p. 574), ainsi que des articles sur le péril jaune (Le Monde nouveau, avril 1925) et sur les rapports entre l'Angleterre et Singapour (Revue mondiale, mai 1924).

19. Couchoud avait visité le Japon de septembre 1903 à mai 1904 et fut hébergé chez Maitre à Tokyo. Il y fit un second séjour de mars à décembre 1912 (Shibata 2010 : 3440 et 46-67).

20. Voir Couchoud (1916), "Les épigrammes lyriques du Japon ", dans Sages et poètes d'Asie, qui reprend une série d'articles parus dans Les Lettres en 1906. La préface de cet ouvrage, rédigée par son "maitre " Anatole France et ajoutée à la $4^{e}$ édition de 1924, fut publiée également dans $J E O\left(\mathrm{n}^{\circ} 2\right.$, janvier 1924, p. 89-98). Couchoud publia aussi dans le $\mathrm{n}^{\circ} 3$ de $J E O$ (février 1924, p. 185-193) un extrait de son journal, "Quinze jours au Japon pendant la guerre russo-japonaise », qui avait été retranché du même livre. Sur l'influence de Couchoud sur le mouvement du haïkaï français, voir Kaneko \& Shibata 1999 ; Shibata 2010 ; Froloff 2006.

21. R. Martinie, en poste à Tokyo de 1903 à 1911 comme attaché naval, avant d'y diriger la succursale de la Banque franco-japonaise à partir de 1912 (Gérard 1919 : 292), publiera notamment des traductions de La Porte (Rieder, coll. « Les prosateurs étrangers modernes ", avec un avant-propos par R. Martinie, 1927) et du cinquième chapitre de Je suis un chat (Bulletin de la Société franco-japonaise de Paris, nº 69, 1928) de Sōseki. Il faut noter aussi, concernant Sōseki, une traduction de Botchan par N. Ogata parue dès 1923 chez Maruzen à Tokyo sous le titre Botchan, ou jeune homme irréfléchi, mais qui ne semble guère avoir été diffusée en France. 
japonaise et l'ukiyo-e $e^{22}$. La plupart des collaborateurs de la revue avaient donc séjourné assez longuement au Japon au début du $\mathrm{xx}^{\mathrm{e}}$ siècle et leur domaine de compétence portait non seulement sur la littérature, les arts et l'histoire du Japon, mais aussi sur les questions politiques et économiques, ce dont témoigne leur projet éditorial qui couvrait un champ relativement large.

La lecture du " programme » de la revue ${ }^{23}$ est particulièrement instructive et fournit des éléments pour comprendre l'état des relations francojaponaises en ce début des années 1920. Il s’agit pour ses fondateurs de " travailler à un rapprochement franco-japonais ». En effet, " en France les sympathies pour le Japon ont toujours été très vives ", même si l'intérêt pour ce pays s'est d'abord concentré autour de ses créations artistiques, avant que l'on ne découvre les "particularités des conceptions morales, religieuses et juridiques du Japon ", ainsi que sa littérature et son histoire. Au Japon, l'influence de la France, considérable dans les domaines du droit, de l'armée et de l'art, était moindre depuis la défaite de 1870 et la progressive " emprise anglo-saxonne ", notamment dans le commerce et dans l'enseignement. Mais la rupture de l'Alliance anglo-japonaise (Nichiei dōmei 日英同盟) - nouée en 1902 et qui prit fin en août 1923 - rebattit les cartes de l'équilibre géopolitique en Asie-Pacifique, incitant le Japon à chercher "ailleurs que dans le monde anglo-saxon les amitiés et les appuis qui [venaient] de lui faire brusquement défaut ». La victoire de la France en 1918 aurait rétabli son prestige au Japon : " un mouvement très net s'est produit vers l'étude de notre langue. Des Japonais amis ont formé le projet d'édifier à Tokyo une Maison de France [nom donné initialement à la future Maison franco-japonaise], et le Gouvernement s'est associé à leur initiative ». Dans ce contexte qui semble favorable à un "rapprochement des deux pays" - même s'il faut sans aucun doute nuancer cette vision très optimiste, qui contraste avec le constat qu'avait fait Paul Claudel en 1922, peu après sa prise de fonction comme ambassadeur au Japon ${ }^{24}-$, la revue

22. L. Aubert était l'auteur notamment de Paix japonaise (Armand Colin, 1908, avec la collaboration de Noël Peri pour les traductions), Américains et Japonais (Armand Colin, 1908) et Les Maîtres de l'estampe japonaise (Armand Colin, 1914).

23. "Notre programme ", JEO, n ${ }^{\circ} 1,1^{\text {er }}$ décembre 1923, p. 1-5.

24. En effet, Claudel note en 1922 l'influence écrasante de l'Allemagne en médecine, en sciences, comme en lettres et en philosophie, et le bilan désolant de l'enseignement du français (Graziani 2013 : 23-24). 


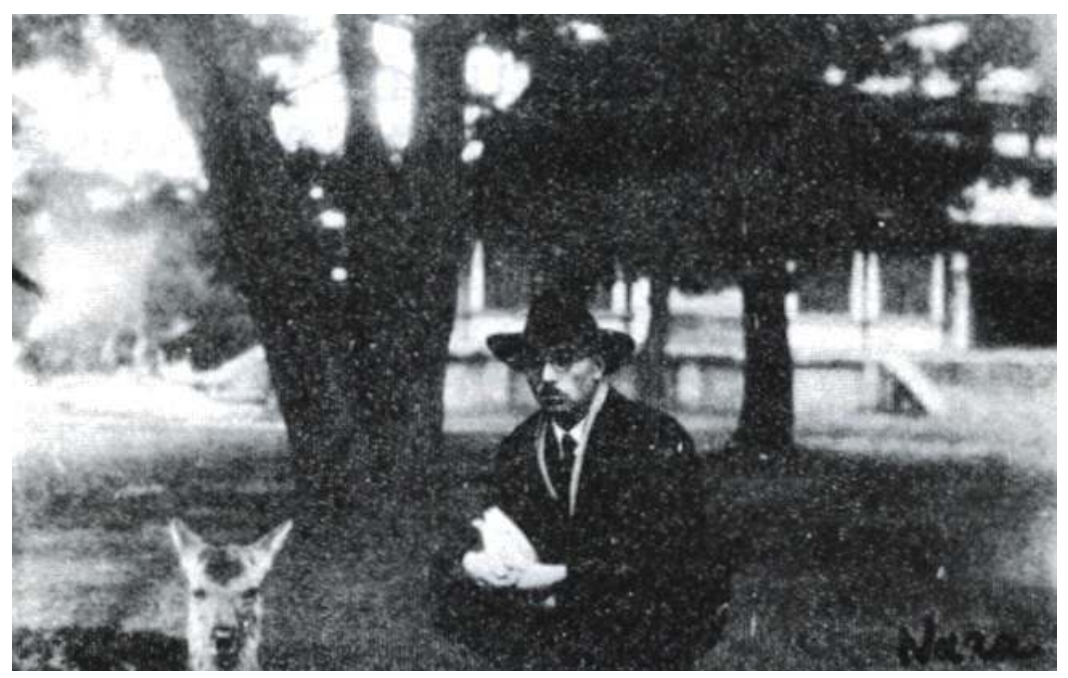

Fig. 7

Charles Haguenauer à Nara en 1925. D'après Mélanges offerts à M. Charles Haguenauer en l'honneur de son quatre-vingtième anniversaire. Études japonaises (Frank 1980).

entend apporter au public français « non pas des impressions ou des dissertations, mais des textes, des documents et des faits, en un mot des éléments d'information et d'appréciation aussi nombreux et aussi précis que possible sur un pays vers lequel le porte une sympathie spontanée, mais insuffisamment avertie ». L'objectif est de traiter très largement de la politique, de la vie économique, des sciences, de l'histoire, de l'art ou de la littérature, et d'éclairer sur la " pensée japonaise » en donnant le plus possible la parole aux Japonais eux-mêmes et en présentant des traductions et des analyses de documents. Des informations seraient en outre apportées ponctuellement sur la Chine et d'autres pays d'Extrême-Orient quand elles peuvent éclairer la compréhension du Japon.

Parmi les collaborateurs importants de la revue notons également Moïse Charles Haguenauer (1896-1976) (fig. 7). Tout juste diplômé de l'École des langues orientales vivantes en japonais, chinois et malais, et de l'École pratique des hautes études - où il fut l'élève de Mauss et des plus grands orientalistes de son temps comme Sylvain Lévi, Marcel Granet, Paul Pelliot 
ou Henri Maspero -, il s'apprêtait à partir pour le Japon pour y mener des études d'ethnographie ${ }^{25}$. Haguenauer deviendra en janvier 1926 le premier pensionnaire et le secrétaire français de la Maison franco-japonaise. Il traduira notamment pour la revue deux nouvelles de Shiga Naoya 志賀直哉 (JEO, n 3, février 1924) et de Mori Ōgai 森鷗外 (JEO, n 11-12, novembre-décembre 1924).

Dans un intéressant article intitulé " Le conflit du Pacifique, la guerre civile en Chine et les tendances actuelles de la politique japonaise ", qu'il envoie de Tokyo le 20 novembre 1924, à la veille de la création de la Maison franco-japonaise, Haguenauer écrit :

« Le Japon s'intéresse actuellement de façon plus vive et plus sympathique que jamais à notre vie sociale, intellectuelle et artistique. Il ne faut pas que ce mouvement reste sans réponse de notre part. Pour cela, il faut que nous apprenions à mieux connaître ce peuple dont on a dit de façon quelquefois mielleuse ou naïve trop de bien, ce qui permet d'en dire tout le mal possible. Il ne faut plus que le Japon ne nous soit connu qu'à travers quelques livres fort beaux, mais en partie périmés (Hearn), à travers quelques récits d'une inqualifiable fausseté (Le Japon, pays de geisha) ou au travers de quelques romans qui dénotent un manque de sympathie évident $(\text { Kimono })^{26}$. " (Haguenauer 1924 : 383)

On comprend combien la revue Japon et Extrême-Orient, en s'associant le concours des meilleurs spécialistes, entendait lutter contre les préjugés et les images d'Épinal qui continuaient de circuler en France sur le Japon à travers la littérature de vulgarisation.

25. Haguenauer arrive au Japon le 30 juin 1924 avec une bourse de la Fondation de Montfort (créée en 1923) pour y étudier la langue et la civilisation japonaises. Il sera nommé pensionnaire de la Maison franco-japonaise en janvier 1926. D’après son curriculum vitae conservé dans les archives du Bureau français de la Maison franco-japonaise. 26. Il s'agit sans doute de références à l'ouvrage de Robert Chauvelot, Le Japon souriant: ses samouraïs, ses bonzes, ses geishas (Paris, Berger-Levrault, 1923), et à celui de John Paris, Kimono (Londres, W. Collins, 1921), histoire romancée d'un mariage anglo-japonais. 


\section{Introduction de la littérature japonaise contemporaine en France}

L'un des objectifs de la revue est de " mieux faire connaître la littérature japonaise classique et contemporaine " sur laquelle on ne disposait alors en France que d' "informations fort superficielles et de seconde main " ${ }^{27}$. De fait, en langue française, il n'existait alors que l'Anthologie de la littérature japonaise des origines au XXe siècle de Michel Revon, parue en 1910 (et à sa $5^{\mathrm{e}}$ réédition en 1923), qui s'arrêtait justement à l'époque de Meiji, d'ailleurs très brièvement présentée, avec pour la prose un seul extrait du roman Hototogisu 不如州 (Le Coucou) de Tokutomi Roka 徳富蘆花 ${ }^{28}$. La revue publia ainsi les toutes premières traductions en français de grands écrivains japonais contemporains, sous la forme d'une douzaine de nouvelles d'auteurs majeurs qui connaîtront par la suite une renommée internationale, rédigées entre les années 1909 et $1923^{29}$. Ces textes furent choisis, traduits

27. "Notre programme ", $J E O, \mathrm{n}^{\circ} 1,1^{\text {er }}$ décembre 1923, p. 4.

28. Il faudra attendre les deux ouvrages majeurs de Georges Bonneau, préparés lorsqu'il fut pensionnaire à la Maison franco-japonaise de 1932 à 1939, pour disposer d'une première histoire de la littérature japonaise qui prenne en compte la période moderne (Bonneau 1938, 1940).

29. Natsume Sōseki (1867-1916) (“Mon camarade " / "Tomodachi » 友達, première partie de Köjin 行人, 1912), Mori Ōgai (1862-1922) ( Le Takasebune » / "Takasebune » 高瀬舟, Chūō kōron 中央公論, janvier 1916), Hasegawa Nyozekan 長谷川如是閑 (18751969) (“Le Cornac » / "Zōya no Kume-san » 象やの夈さん, Chūō kōron, janvier 1921), Nagai Kafū 永井荷風 (1879-1959) (“Le Renard » / "Kitsune » 狐, 1909, extrait du recueil Botan no kyaku 牡丹の客, 1911), Shiga Naoya (1883-1971) ("Le Crime du jongleur " / "Han no hanzai » 范の犯罪, extrait du recueil Suzu 寿々, 1922 ; “Un vieillard " / "Rōjin » 老人, février 1911, extrait du recueil Yoru no hikari 夜の光, 1918), Okada Yachiyo 岡田八千代 (1883-1962) ("Les trois jours » / " Mikka »三, extrait du recueil Enogu bako 絵具箱, 1912), Tanizaki Jun.ichirō 谷崎潤一郎 (1886-1965) («Le Tatouage » " Shisei » 刺青, extrait du recueil éponyme Shisei, 1911), Kikuchi Kan 菊 池寛 (1888-1948) (“Le double suicide de Shimabara » “ Shimabara shinjū »島原心中, extrait du recueil Dōri 道理, 1921), Satomi Ton 里見毫 (1888-1983) ("Le bruit des vagues de la rivière » / "Kawanami no oto »川波の音, Chūō kōron, janvier 1921), Kubota Mantarō 久保田萬太郎 (1889-1963) (“L'été qui commence » “ Hatsunatsu »はつ夏, extrait du recueil Yuki 雪, 1913), Akutagawa Ryūnosuke 芥川龍之介 (1892-1927) ( La Bécassine " / "Yamashigi » 山鴫, Chūō kōron, janvier 1921, "Les poupées » / "Hina » 雛, Chūō kōron, mars 1923). 


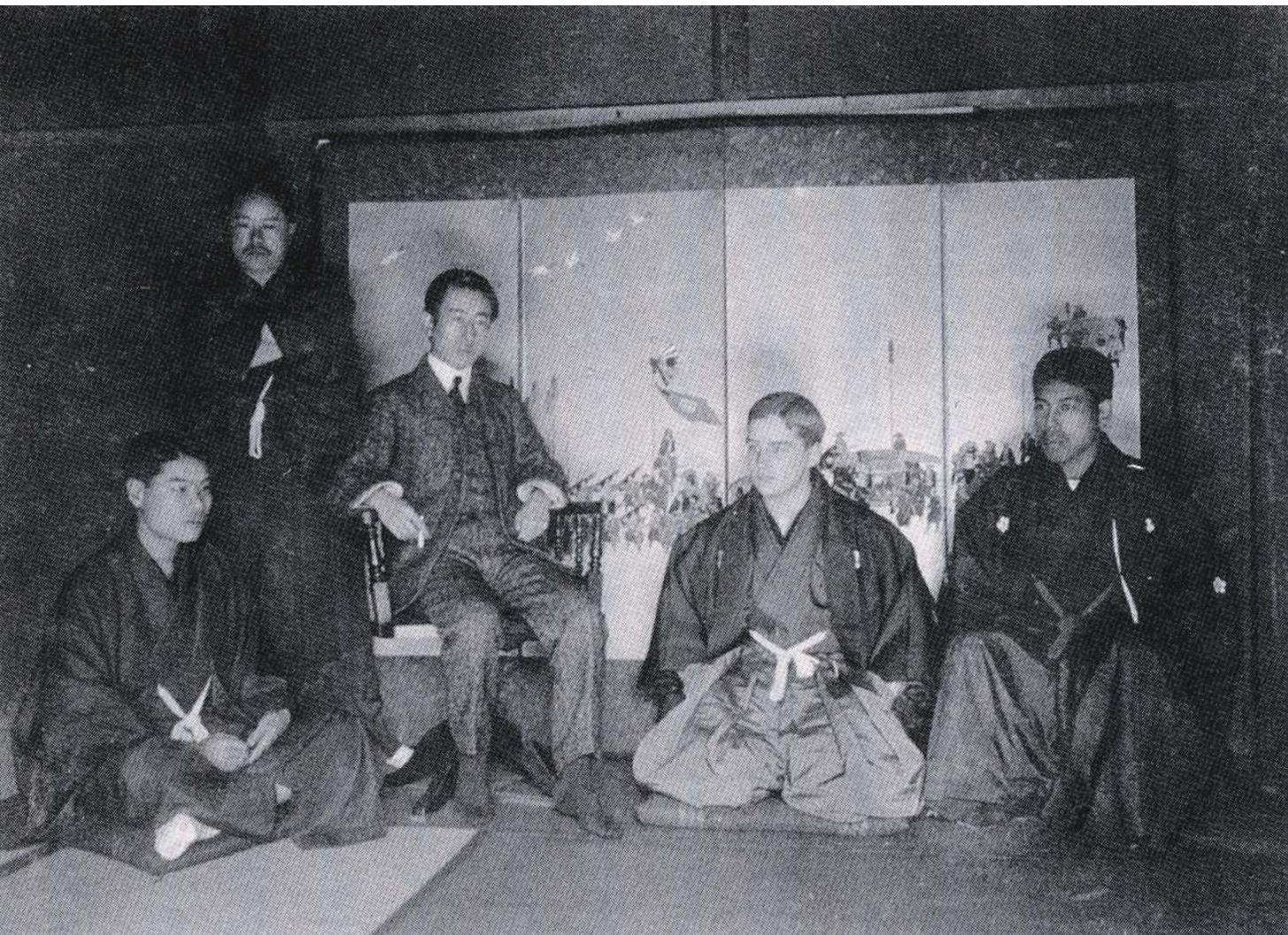

Fig. 8

Serge Elisséev et Komiya Toyotaka

(à sa droite sur la chaise),

à Tokyo, vers 1909-1914.

D’après Kurata 2007. 
et présentés de manière remarquable, essentiellement par Elisséev, mais aussi par Haguenauer, Martinie et par le poète et traducteur Horiguchi Daigaku 堀口大學 (1892-1981), qui séjournait alors à Paris.

Comme nous l'avons vu, Elisséev avait fréquenté le milieu littéraire de Tokyo au début des années 1910, notamment le Salon du Jeudi (Mokuyōkai 木曜會) qui se tenait au domicile de Natsume Sōseki, où il côtoya entre autres Akutagawa Ryūnosuke, Morita Sōhei 森田草平 et Nagai Kafü ${ }^{30}$. Il fréquenta aussi des écrivains comme Tanizaki Jun.ichirō et Kubota Mantarō. Il se noua en particulier d'amitié avec Komiya Toyotaka 小宮豐隆 (fig. 8) (1884-1966), spécialiste de littérature allemande, critique littéraire et disciple de Sōseki, dont il éditera les œuvres complètes. C’est cette littérature contemporaine découverte en " temps réel » lors de son long séjour à Tokyo qu'Elisséev a eu souci de présenter et de traduire dans une langue admirable pour Japon et Extrême-Orient. On est frappé par la justesse dans le choix des textes, qu'il s'agisse d'écrivains déjà classiques et récemment disparus, comme Sōseki (mort en 1916) ou Mori Ōgai (mort en 1922), de grands auteurs déjà largement établis, comme Nagai Kafū ou Hasegawa Nyozekan, ou d'auteurs de la génération montante, comme Shiga Naoya, Tanizaki, Satomi Ton, Kikuchi Kan ou encore Akutagawa, dont deux nouvelles traduites dans Japon et Extrême-Orient, "La Bécassine " ( Yamashigi ») et "Les poupées » («Hina ), avaient été publiées peu auparavant, respectivement en janvier 1921 et en mars 1923, dans la revue Chūō kōron.

Elisséev lisait en effet à Paris les grandes revues littéraires que sont $C h \bar{u} \bar{o}$ kōron (il cite des numéros de 1912, 1921 et 1923) et Shinshōsetsu 新小説 (il cite un numéro de 1922 consacré à Ōgai) et les plus récents ouvrages d'histoire littéraire, comme la somme du critique Takasu Baikei 高須梅溪, Kindai bungei shiron 近代文藝史論 (Essai sur l'histoire des lettres et des arts de la période moderne), parue en mai 1921, dont il fait une longue et

30. La première rencontre entre Elisséev et Sōseki remonterait au 24 juin 1909, d'après une mention dans le journal de Sōseki (Kurata 2007 : 50). Sōseki fit par la suite écrire Elisséev sur la littérature russe, dans la rubrique littéraire de l'Asahi shinbun (sept chroniques entre décembre 1909 et février 1912) dont il avait la responsabilité (Kurata 2007 : 56-58, 191). Le nom d'Elisséev est mentionné également dans un texte d'Akutagawa (Kurata $2007: 54$ ). 
pertinente recension dans le troisième numéro de la revue $e^{31}$. Dans un autre texte où il brosse un remarquable tableau de la littérature moderne depuis les dernières années du XIX ${ }^{\mathrm{e}}$ siècle ${ }^{32}$ - qui le montre très au courant de la critique -, il présente les grandes revues littéraires contemporaines que sont Mita bungaku 三田文學 (1910-), Waseda bungaku 早稲田文學 (1891-) et Shirakaba 白樺 (1910-1923), ou encore le tout récent périodique Bungei shunjū 文藝春秋, fondé en janvier 1923 et «qui ne publie que la vérité concernant la littérature et où aucune œuvre d'un caractère imaginatif n'est admise ». Elisséev montre son penchant pour Shiga Naoya, qu'il présente comme "l'un des plus brillants écrivains de la génération actuelle ". Il évoque aussi le courant des « écrivains prolétariens " (Nakanishi Inosuke 中 西伊之助, Miyachi Karoku 宮地嘉六, etc.) auquel la revue Chūō kōron / The Central Review avait consacré un article dans son numéro spécial de juin $1923^{33}$, en concluant : " nous pouvons considérer la littérature japonaise comme l'une des plus vivantes qui soient à l'heure actuelle; les écrivains nippons semblent dignes d'occuper une place importante dans la littérature mondiale ". Les notes de présentation des écrivains qu'Elisséev traduisit pour Japon et Extrême-Orient montrent en outre toute l'attention qu'il portait aux questions de style.

Toutes les traductions réalisées par Elisséev furent réunies dans le recueil Neuf nouvelles japonaises (fig. 9), publié à Paris chez l'éditeur orientaliste Gérard Van Est dès 1924 et qui constitua la toute première publication française consacrée à la littérature japonaise contemporaine (Elisséev 1924). Cette anthologie fut saluée comme une tentative inédite de "donner une image assez complète et assez fidèle des divers courants de cette littérature »,

31. "Une histoire de la littérature japonaise contemporaine ", JEO, n 3, février 1924, p. $281-288$.

32. S. Elisséev, "Panorama de la littérature contemporaine au Japon " (rédigé en juillet 1925) publié dans Tanizaki, Puisque je l'aime (version française de S. Asada, H. Yokoyama et Charles Jacob), Paris, éditions Émile-Paul frères, 1925, p. 153-161. Cet ouvrage est la traduction d'un drame en trois actes de Tanizaki, Ai sureba koso 愛すれ ばこそ, édité au Japon dans les revues Kaizō 改造 (déc. 1921) et Chūō kōron (jan. 1922). 33. Chūō kōron, $38^{\mathrm{e}}$ année, $\mathrm{n}^{\circ} 7$, juin 1923 , numéro spécial : «Chishiki kaikyū to musan kaikyū gō » 知識階級と無産階級號 (Intelligentsia et prolétariat). 


\section{EXTRAIT DE “JAPON ET EXTREME-ORIENT"}

\section{NEUF NOUVELLES JAPONAISES}

traduites par

\section{Serge ÉLISSEEV}

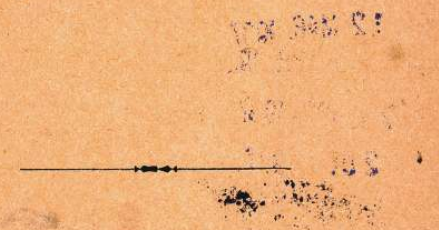

G. VAN CEST, EDITEUR

63, Boulevard Haussmann, 63

PARIS

1924

Fig. 9

Neuf nouvelles japonaises,

traduites par Serge Elisséev,

1924. Bibliothèque de la

Maison franco-japonaise. 
en dehors de tout exotisme trop séducteur, et appréciée par la qualité du style des nouvelles, parfaitement servie par le traducteur ${ }^{34}$.

Un autre volume, qui comporte une demi-douzaine de traductions d'écrivains qu'Elisséev avait fréquentés au Japon (Kafū, Tanizaki, Morita Sōhei, Shiga Naoya, Hasegawa Nyozekan, Arai Kiichi 新井紀一), paraîtra en 1927 sous le titre Le jardin des pivoines par Nagaï Kafû suivi de cinq récits

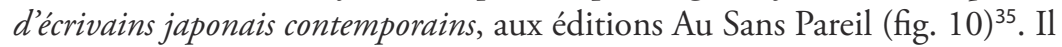
sera remarqué lui aussi par la critique française, qui n'hésitera pas à comparer l'inspiration de ces textes à ceux du James Joyce de Gens de Dublinn'.

Cette qualité littéraire de la revue n'échappa pas à Claudel, qui la lisait au Japon, et l'appréciait particulièrement, comme en témoigne ce qu'il déclara en 1925 dans une interview donnée aux Nouvelles Littéraires, alors qu'il était en congé en France : "Je vous engage à lire les merveilleuses nouvelles qui ont paru dans un petit périodique, malheureusement défunt aujourd'hui, qui paraissait sous la direction de M. Maitre et qui s'appelait Japon et Extrême-Orient. C'est aussi bon que du Tchekov. " (Claudel 1991 : 125) Plusieurs numéros de la revue subsistent d'ailleurs dans la bibliothèque de Claudel au château de Brangues ${ }^{37}$.

Elisséev rédigea aussi un intéressant article sur "Jippensha Ikku et le Hizakurige » $\left(J E O \mathrm{n}^{\circ} 5\right.$, avril 1924, p. 639-648), le grand romancier populaire du début du XIX ${ }^{\mathrm{e}}$ siècle et son chef-d'œuvre drolatique, $\grave{A}$ pied sur le Tōkaidō (Tökai dōchū hizakurige 東海道中膝栗毛, 1810-1822), et il évoqua

34. Maurice Betz, "Notes critiques : Neuf nouvelles japonaises " (Tanizaki 1925 : 162-163).

35. La couverture de l'ouvrage sera illustrée par le graveur Hasegawa Kiyoshi 長谷川 潔 (1891-1980), installé en France depuis 1919. Les textes réunis dans ce recueil sont : Botan no kyaku 牡丹の客 ("Le Jardin des pivoines », 1909) de Nagai Kafū, Akunichi 惡日 ("La journée malheureuse », Chūō kōron, juin 1923) d’Arai Kiichi - écrivain du courant de la littérature prolétarienne de l'époque de Taishō-, Takibi 焚火 ("Les Feux ", 1920) de Shiga Naoya, Aru kafé no musume 或るカフェーの娘 ("La Fille du café », 1921) de Hasegawa Nyozekan, Natori deshi 名取弟子 ("L'Élève diplômée ", 1912) de Morita Sōhei, et Himitsu 秘密 ("Le Secret », 1911) de Tanizaki Jun.ichirō.

36. Voir notamment la critique élogieuse publiée par Marcel Arland dans La Nouvelle revue française, $\mathrm{n}^{\circ} 166,1^{\text {er }}$ juillet 1927 , p. 259-260.

37. Les numéros 4, 5, 7-8, 10 (deux exemplaires) et 11-12 de Japon et Extrême-Orient figurent dans l'inventaire de la bibliothèque de Claudel (Bazaud 1979 : 194). Voir aussi Mayaux (2010: 154). 


\section{LE JARDIN DES PIVOINES P A R \\ NAGAÏ KAFÛ}

SUIVI DE

CINQ RÉCITS D'ÉCRIVAINS JAPONAIS CONTEMPORAINS

TRADUCTION DE SERGE ELISSÉEV

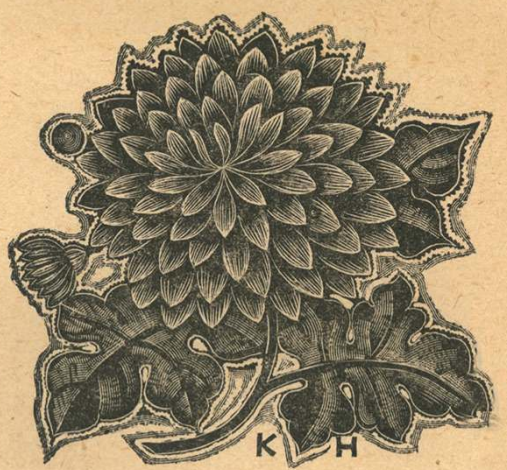

A P A R I S

A U SA N P A REIL

37 , AVENUE KLÉBER, 37

M. C M.X X V I I.

Fig. 10

Le jardin des pivoines par

Nagaï Kafû, traduit par Serge

Elisséev, 1927. Bibliothèque de

la Maison franco-japonaise. 
la publication de fragments étendus de la traduction de ce roman par Noël Peri (décédé accidentellement à Hanoi en 1922), mais qui ne parurent finalement pas. Maitre, de son côté, édita dans Japon et Extrême-Orient une série d'une douzaine de traductions de "farces japonaises " (kyōgen) réalisées par Peri, dont il avait récupéré les manuscrits après sa disparition, en se proposant de publier ceux qui pouvaient être utilisés ${ }^{38}$. Ces traductions ${ }^{39}$ - les toutes premières en français de ce type de texte théâtral parodique avaient été réalisées d'après l'édition supervisée par l'écrivain Kōda Rohan ${ }^{40}$.

\section{Informations sur la vie politique et sociale au Japon et les relations internationales}

Ces traductions littéraires ne sont pas le seul intérêt de Japon et ExtrêmeOrient, revue généraliste qui publia également des textes d'opinion, des documents, des chroniques sur l'actualité et des comptes rendus d'ouvrages $^{41}$. Elle donna également la parole à des universitaires et à des journalistes japonais, ainsi qu’à des personnalités politiques, comme Takahashi Korekiyo 高橋是清 (1854-1936), Premier ministre de 1921 à 1922 et président du parti Rikken seikyūkai 立憲政友會. Dans « Les problèmes essentiels de la politique extérieure du Japon ", celui-ci présente la position du gouvernement sur les questions alors primordiales pour le Japon de la liberté d'émigration (pour faire face au problème de la surpopulation), de l'appro-

38. Aurousseau 1925 : 617 ; Maitre 1924 : 306, note 1 : "Nous comptons publier ici même, outre les kyōgen, le Hiza-kurige. Les travaux d'un caractère plus technique seront réservés pour le Bulletin de l'École Française d'Extrême-Orient. "

39. Ces onze traductions parues dans les numéros 4 à 9 de Japon et Extrême-Orient seront rééditées dans Noël Peri 1944 : 397-483. Il s'agit de Suminuri onna 墨塗女 ( La femme barbouillée d'encre ), Yao jizō八尾地藏 ( Le jizō de Yao »), Sōhachi 宗八 ( Sōhachi »), Koppi 骨皮 ("Les os et la peau»), Niō 仁王 ( Le Ni-ō »), Tsurigitsune 釣 狐 ("Le renard pris au piège »), Fusenai kyō 布施無經 ("Pas d'aumône! "), Kamabara 鎌 腹 (“Un coup de serpe dans le ventre»), Busu 附子 ("Le poison»), Rokunin sō 六人僧 ( Tout religieux!») et Hanako 花子 (" Mademoiselle Hana »).

40. Kōda Rohan 幸田露伴, Kyōgen zenshū 狂言全集. 3 vol., Tokyo, Hakubunkan 博文館, 1903.

41. Les différentes rubriques de la revue sont, outre les traductions en début de volume: "Variétés ", "Chronique ", " Opinions ", « Documents ", " Bibliographie ». 
visionnement alimentaire et en matières premières, et du désarmement, en prônant le principe de la "porte ouverte » dans le monde entier, en particulier en Chine, en Russie et dans le Pacifique ${ }^{42}$.

La revue traite aussi des grandes questions d'actualité et de société : le statut des femmes, la politique extérieure du Japon, le projet de loi pour le suffrage universel, les syndicats et les groupements militants, la vie politique ou encore les dégâts et la reconstruction de Tokyo et de Yokohama après le grand séisme du $1^{\text {er }}$ septembre 1923. Elle accorde de l'importance à l'actualité géopolitique et diplomatique, comme dans le premier numéro qui comporte deux textes ${ }^{43}$ sur les rapports entre le Japon et deux grandes puissances, Russie et États-Unis, à la suite d'une part des difficiles négociations pour un accord politique, commercial et militaire menées avec les Russes entre 1921 et 1923 (en particulier pour la protection des intérêts japonais en Sibérie) et, d'autre part, des accords de Washington (traité des quatre puissances sur le statut du Pacifique de 1921 et traité naval de désarmement de 1922). Les propositions faites par le Japon au sein de la jeune Société des Nations, dans le contexte du conflit migratoire avec les ÉtatsUnis, sont également largement rapportées ${ }^{44}$.

Notons, parmi les textes les plus intéressants, des documents très précis sur « Le mouvement de la population japonaise en 1922 " $\left(J E O \mathrm{n}^{\circ} 1\right)$, sur "La situation de la femme au Japon " $\left(J E O \mathrm{n}^{\circ} 2\right)$, ou "Le mouvement social au Japon. Les groupements et les hommes " $\left(J E O \mathrm{n}^{\circ} 3\right)$. Ces articles de synthèse, publiés dans la rubrique "Documents ", se distinguent par la qualité et la fiabilité de leurs informations. Ils s'appuient sur des sources japonaises directes : quotidiens, statistiques tirées du Journal officiel (Kanpō 官報) et revues spécialisées, comme Gaikō jihō 外交時報 - Revue diplomatique, ou généralistes, comme Kaizō, périodique de gauche qui traite des question sociales, ou Taiyō 太陽. On note en particulier un grand nombre de références à la presse quotidienne, avec pas moins d'une douzaine de journaux ${ }^{45}$ cités régulièrement, qui étaient lus et analysés avec attention par

42. JEO, n² 2, janvier 1924, p. 103-115.

43. Eugène Vergnaud [pseudonyme de Claude Maitre], "Japon et Russie ", JEO, n 1, décembre 1923, p. 6-23 et "Après les accords de Washington ", p. 69-71.

44. JEO, $\mathrm{n}^{\circ} 10$, octobre 1924 , p. 256-268.

45. Chūō shinbun, Hōchi shinbun, Jiji shinpō, Kokumin shinbun, Ōsaka Asahi shinbun, Ōsaka Jiji shinpō, Ōsaka Mainichi shinbun, Tökyō Asahi shinbun, Tōkyō nichinichi 


\section{Le "Parti Prolétatre" *}

- Dans le numéro du mois de septembre de la revue japonaise Le Marxisme, Sakai Toshihiko écrit que les libéraux de gauche, les socialistes de la droite et les communistes veulent former un nouveau parti politique sous le nom de "Parti Prolétaire ".

Il faut avouer que le mouvement prolétaire au Japon a subi des changements notables pendant les derniers trente ans, mais il est encore dans l'état qui était celui du prolétariat d'Europe, il y a cinquante ans. Le parti social-démocrate fut constitué au Japon il y a vingt-cing ans par M. J. Abe, professeur à l'Université libre de Waseda, par MM. Katakami, D. Kotoku, S. Katayama et autres. Mais dès son apparition ce parti fut dissout par le Gouvernement japonais.

Cinq ans plus tard, un nouveau parti socialiste fut créé par Katayama et Sakai, ce parti qui comptait environ 200 membres, eut une existence brève. En 1907, ils organisèrent une assemblée pour célébrer la venue du pionnier du mouvement ouvrier en Angleterre, Keir Hardie, et discutèrent passionnément le problème du suffrage universel et de l'action directe. Ils entrèrent en collaboration avec le parti des socialistes étatistes, fondé par Yamaji Yakichi et entamèrent une lutte contre l'augmentation du tarif des tramways.

Après le procès des anarchistes qui, d'après la police japonaise, avaient organisé un complot contre la vie de l'Empereur Meiji, tout mouvement socialiste devint impossible au Japon pendant plusieurs années. En 1920, il fut question de la création d'une ligue socialiste qui devait englober les représentants des différents groupements socialistes. Pendant la grande guerre de nouveaux partis socialistes et ouvriers se sont formés comme le Yuaikwai par exemple. Il faut noter que, malgré la supression par les autorités de deux groupements communistes, les groupements socialistes continuent à exister. Dernièrement on parlait beaucoup de l'organisation d'un parti prolétarien et la Société pour les Études politiques a organisé un meeting important à ce sujet.

Il faut constater que l'aile gauche de l'ancien parti libéral,

\section{Fig. 11}

"Le "Parti Prolétaire" »

(JEO, $n^{\circ}$ 9, septembre 1924).

Bibliothèque de la Maison

franco-japonaise. 
les rédacteurs de la revue, dans un souci de montrer la variété de l'opinion japonaise. En cela, Japon et Extrême-Orient est remarquable et sans précédent dans le monde éditorial français.

La revue explore un champ vaste et fournit des informations sur la politique gouvernementale, mais aussi sur les opinions de toutes tendances politiques. Ainsi relate-t-elle, dans son numéro de septembre 1924, le projet de création d'un "parti prolétaire " proposé le même mois par Sakai Toshihiko 堺利彦 dans la revue du Parti communiste, Marukusu shugi $\checkmark$ ルクス主義 - Der Marxismus ${ }^{46}$ (fig. 11). Les traductions tirées des revues japonaises paraissent donc avec très peu de décalage par rapport à leur publication au Japon, ce qui montre à quel point l'information circule déjà rapidement à cette époque entre les deux pays.

Les articles d'opinion sont assez peu nombreux, car il s'agit moins pour la revue de se lancer dans des polémiques que de publier des faits solidement étayés sur l'actualité japonaise. Ils sont réunis dans une rubrique du même titre. Il en paraîtra six en tout : "La reconstruction de l'ambassade de France à Tōkyō " ( $\mathrm{n}^{\circ} 3$, par Georges Alsot), "Le monopole de la TSF en Chine " ( $\mathrm{n}^{\circ} 4$, par Ueda Eisaku), "La Chine vue par un journaliste japonais » ( $\mathrm{n}^{\circ}$ 6, par Hanzawa Gyokujō 半澤玉城, rédacteur en chef de la revue Gaikō jihō), "La question de l'immigration japonaise aux ÉtatsUnis " ( ${ }^{\circ} 6$, par C. Maitre), "Ce que devrait être la politique extérieure du cabinet Katō » $\left(\mathrm{n}^{\circ} 10\right.$, repris de la revue Gaikō jihō), et « Le conflit du Pacifique, la guerre civile en Chine et les tendances actuelles de la politique japonaise » ( $\mathrm{n}^{\circ} 11-12$, par M. Haguenauer).

La revue donne aussi la parole à des chercheurs japonais qui séjournent en France, comme le jeune ethnologue Matsumoto Nobuhiro 松本信廣 (1897-1981), arrivé à Paris en 1924 pour y préparer sa thèse en Sorbonne et suivre les enseignements de Mauss, de Granet et de Jean Przyluski, titulaire de la chaire d'annamite à l'École nationale des langues orientales vivantes. Il y publie un instructif état de la recherche sur les études de folklore au

shinbun, Yomiuri shinbun, Yorozu shinbun et quelques journaux anglophones comme le Japan Weekly Chronicle ou la Far Eastern Review.

46. "Le "Parti Prolétaire" ", JEO, n 9, septembre 1924, p. 193-194. Présentation du texte de Sakai Toshihiko, “Musan-tō soshiki ni kan-suru iken » 無産黨組織に關する意 見 (Point de vue sur le Parti prolétaire), Marukusu shugi, vol. 1, n 5, septembre 1924, p. 329-338. 
Japon $^{47}$, alors naissantes, en présentant les travaux des fondateurs de la discipline que sont Yanagita Kunio 柳田國男, Orikuchi Shinobu 折口信夫 ou Minakata Kumagusu 南方熊楠, folkloriste et botaniste (fig. 12). À son retour au Japon, Matsumoto occupera une chaire à la faculté des lettres de l'université Keiō et deviendra l'un des fondateurs de la vietnamologie japonaise, entretenant des liens étroits avec l'École française d'ExtrêmeOrient, notamment par l'intermédiaire d'Émile Gaspardone, pensionnaire à la Maison franco-japonaise de 1930 à 1931 (Roustan 2008 : 43-44).

La revue présente en outre dans la rubrique "Bibliographie » de longs comptes rendus d'ouvrages universitaires japonais majeurs et parmi les plus récents sur la littérature, le théâtre ${ }^{48}$, l'archéologie ou les études de folklore : S. Elisséev y publie une étude détaillée des douze premiers volumes de la collection Rohen sōsho 爐邊叢書 ( (Au coin du feu »), éditée par Yanagita Kunio entre 1919 et 1924, qui réunit des légendes, des contes et des chansons populaires de différentes provinces du Japon ou des études sur les fêtes religieuses ${ }^{49}$.

Japon et Extrême-Orient était une revue portée à bout de bras par son directeur, Claude Maitre, qui y contribuait sous son vrai nom et sous celui de sa mère (en signant Eugène Vergnaud), aussi bien par des traductions, des chroniques de la vie politique et sociale que des comptes rendus d'ouvrages japonais. La maladie qui le frappa au printemps 1924 condamna malheureusement la revue à disparaître après seulement un an d'existence, en décembre

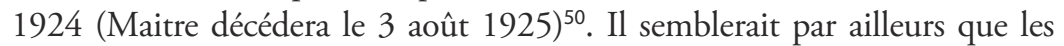

47. Matsumoto Nobuhiro, "L'état actuel des études de folklore au Japon ", JEO, n ${ }^{\circ} 10$, octobre 1924, p. 228-239. Matsumoto publiera en 1928 à Paris deux ouvrages tirés de sa thèse : Essais sur la mythologie japonaise (Librairie orientaliste Paul Geuthner, coll. " AustroAsiatica ", t. I) et Le japonais et les langues austroasiatiques : étude de vocabulaire comparé (Librairie orientaliste Paul Geuthner, coll. "Austro-Asiatica », t. II). Il publiera également dans le Bulletin de la Maison franco-japonaise (t. II, n³ 3-4, 1930, p. 1-13), « La légende de Kogorō le charbonnier (炭焼小五郎がこと) », d'après un article de Yanagita Kunio.

48. S. Elisséev, "Un nouveau livre sur le théâtre japonais ", JEO, n 1, décembre 1923 , p. 77-87. Recension de Sekine Mokuan 關根黙庵, Kabukigeki to sono haiyū 歌舞伎劇と其 俳優 (Le théâtre kabuki et ses acteurs), Tokyo, Kokushi kōshūkai 國史講習會, 1922.

49. S. Elisséev, "Une collection de folklore japonais ", JEO, n 10, octobre 1924 , p. 279-292.

50. Chacun des dix volumes de la revue comporte une centaine de pages, soit au total 980 pages. Ils seront réunis en tome par période de six mois (tome premier : décembre 


\section{L'état actuel des études de folklore au Japon}

Il existe, depuis l'époque des Tokugawa, c'està-dire depuis le XVII ${ }^{\mathrm{e}}$ siècle, des recueils intéressants où sont relatés les usages, les coutumes, les chansons, les légendes et les croyances populaires du Japon. Mais les études comparatives et synthétiques de la vie du peuple dans l'antiquité, les essais systématiques de reconstitution de cette vie sont de date récente. Parmi les personnes qui présidèrent à ces études, l'une des plus influentes a été M. Yanagita Kunio.

M. Yanagita Kunio, licencié en droit, a été longtemps secrétaire du bureau de la Chambre des Pairs. Il occupait alors les loisirs de sa charge à grouper les légendes répandues dans le peuple japonais. Récemment il a donné sa démission pour se consacrer tout entier au folklore de son pays. Enfin, l'Université libre de Keiô, qui a fondé une chaire de folklore, s'est adressée à M. Yanagita. Il faut se réjouir de l'initiative prise par cette Université et souhaiter la création de chaires semblables dans les grandes institutions.

M. Yanagita Kunio n'a pas seulement une connaissance approfondie des ouvrages anciens des "descriptions de provinces " (1) et des différentes études

(1) Chishi.

Fig. 12

« L'état actuel des études de folklore au

Japon » de Matsumoto Nobuhiro

(JEO, $\mathrm{n}^{\circ} 10$, octobre 1924). Bibliothèque

de la Maison franco-japonaise. 
64 | Christophe MARQUET | Le développement de la japonologie en France...

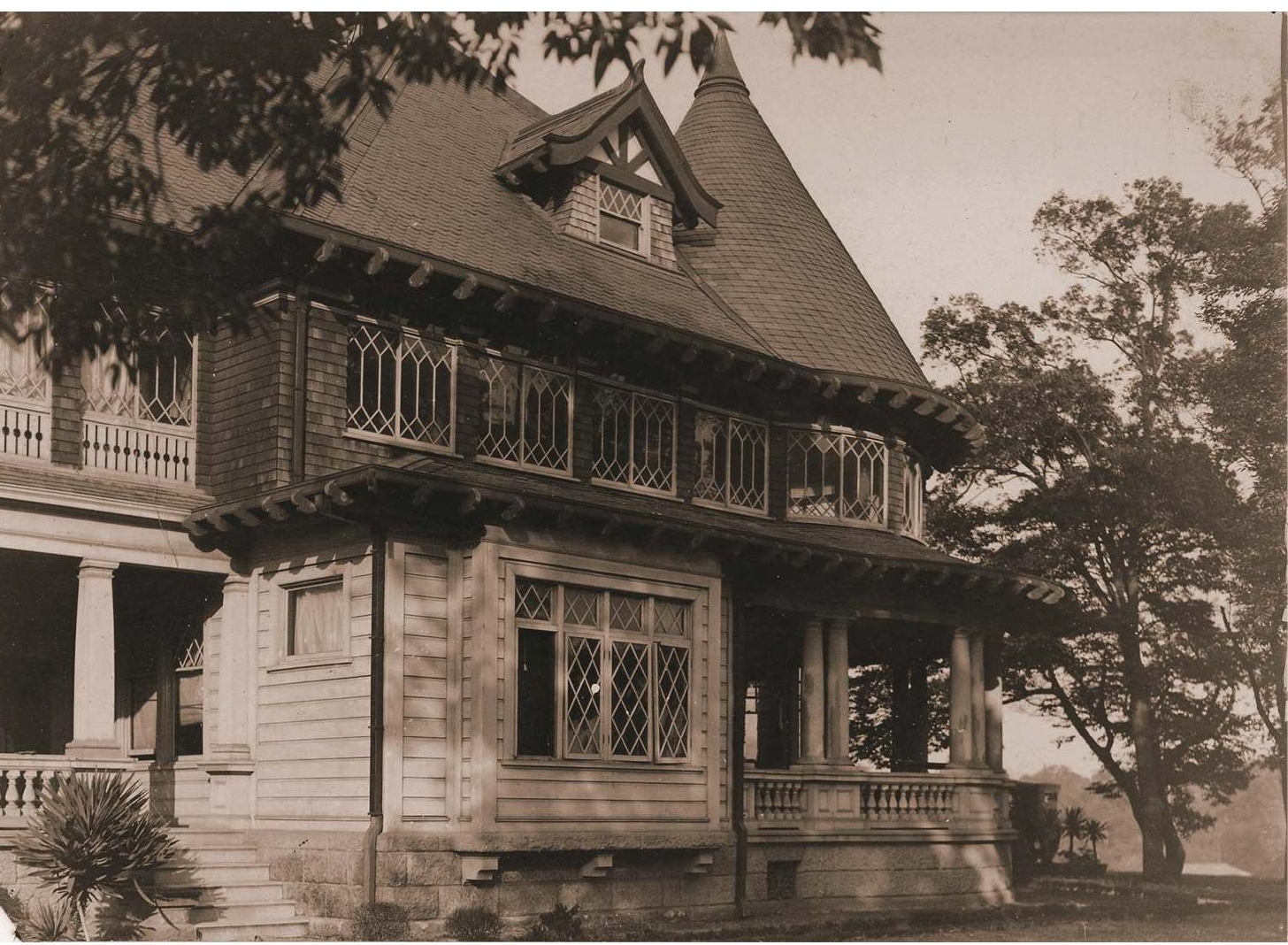

\section{Fig. 13}

La villa de Murai Kichibei à Nagatachō, à Tokyo, où fut installée la Maison franco-japonaise en 1924. @ Fondation d'utilité publique Maison franco-japonaise. 
entreprises françaises et japonaises qui participaient au financement de la revue aient estimé que son orientation était trop littéraire et pas assez tournée vers l'économie ${ }^{51}$.

\section{En guise de conclusion : une nouvelle étape de la japonologie française}

Évoquons en conclusion les liens entre la revue Japon et Extrême-Orient, la Maison franco-japonaise et le musée Guimet. La Maison franco-japonaise fut créée en décembre 1924, au moment même où disparaissait Japon et Extrême-Orient, à une période que l'on peut considérer comme le véritable début des études japonaises en langue française. Le projet de cette maison, mentionné dès le premier numéro de la revue, fut annoncé également dans le dernier numéro, avec un bref article anonyme sur la mise à disposition par Murai Kichibei 村井吉兵衞 (1864-1926), industriel du tabac et philanthrope, d'une villa lui appartenant pour la future "Maison de France " (fig. 13) $)^{52}$.

Claude Maitre sera d'ailleurs choisi, avec Sylvain Lévi et Paul Pelliot, professeurs au Collège de France, comme membre du "Comité français de la Maison de France " mis en place au ministère des Affaires étrangères sous la présidence de Claudel en juillet $1925^{53}$. La Maison franco-japonaise commencera ses activités scientifiques au début 1926, un peu plus d'un an après la disparition de la revue, et fournira à la France une base avancée pour le développement des études japonaises. Cette base manquait à l'École française d'Extrême-Orient, qui n'installera au Japon un centre permanent que bien plus tard, à la fin des années 1960. Cette institution, dans l'idée de son premier directeur, Sylvain Lévi (en poste de septembre 1926 à mai 1928),

1923-juin 1924, 584 pages; tome second : juillet 1924-décembre 1924, 396 pages).

51. La revue comporte des publicités d'entreprises d'import-export, de négociants et de banques : Mitsubishi, la maison d'import-export Takashima, le marchand d'art Vignier, les soieries du Japon Horikoshi, l'importateur de perles fines Banno, la Banque francojaponaise, etc.

52. "Un ami de la France : M. Murai Kichibei ", JEO, n 11-12, novembre-décembre 1924, p. 393-394.

53. Rapport tapuscrit du Comité français de la MFJ, daté du 29 juillet 1925. Maitre est excusé pour maladie. Archives du Bureau français de la Maison franco-japonaise. 
avait vocation «à répandre en France, et par le véhicule de la langue française, dans le monde occidental, une représentation plus réelle et plus juste de ce Japon qu'une tradition tenace s'obstine à peindre avec des couleurs artificielles à l'usage de l'Occident ${ }^{54}$ ». Ce projet scientifique s'inscrivait parfaitement dans l'esprit de la défunte revue Japon et Extrême-Orient.

Joseph Hackin (1886-1941), archéologue spécialiste de l'Afghanistan, directeur du musée Guimet depuis 1923, sera le troisième directeur français de la Maison franco-japonaise, de 1930 à 1933, période pendant laquelle il participera à la fameuse Croisière jaune organisée par André Citroën. Il avait eu comme collaborateur au musée Guimet Claude Maitre et assista donc à la naissance de la revue Japon et Extrême-Orient. Il contribua pour sa part à la création durant la même période de la Revue des Arts asiatiques (fondée en mai 1924), dirigée par le romancier et critique Edmond Jaloux, puis par Paul Pelliot à partir de 1928, devenant les "Annales du musée Guimet " (fig. 14) ${ }^{55}$. Cette revue qui sous son titre actuel, Arts Asiatiques, est encore l'unique périodique académique en langue française sur les arts de l'Asie, marqua le début des recherches scientifiques sur l'art japonais. Elisséev en fut un actif collaborateur. Il publia plusieurs articles de synthèse, sur la peinture de paysage au Japon ou sur l'école de peinture des $\mathrm{Kano}^{-56}$. Il y présenta aussi les travaux de spécialistes japonais, comme ceux d'Umehara Sueji 梅原末治 (membre de la Commission archéologique auprès du gouvernement général de la Corée) sur l'archéologie de la Corée $e^{57}$, de l'archéologue Morimoto Rokuji 森本六爾 sur l'âge du bronze au Japon ${ }^{58}$, ou

54. Préface de Sylvain Lévi au Bulletin de la Maison franco-japonaise, $\mathrm{n}^{\circ}$ 1, "Matériaux japonais pour l'étude du bouddhisme ", 1927, p. 1.

55. La création de la revue est saluée avec enthousiasme par Claude Maitre dans «Une revue française des arts de l'Asie ", JEO, n 6, mai 1924, p. 580-582.

56. S. Elisséev, "Sur le paysage à l'encre de Chine du Japon ", Revue des Arts asiatiques, $\mathrm{II}^{\mathrm{e}}$ année, $\mathrm{n}^{\circ} 2$, juin 1925, p. 30-38; S. Elisséev, "Les peintres de l'école Kanō ", Revue des Arts asiatiques, $\mathrm{II}^{\mathrm{e}}$ année, $\mathrm{n}^{\circ}$ 4, décembre 1925, p. 14-26.

57. Sueji Umehara, "Deux grandes découvertes archéologiques en Corée " (article rédigé en japonais à Paris en février 1926 et traduit par Elisséev), Revue des Arts asiatiques, III ${ }^{\mathrm{e}}$ année, $\mathrm{n}^{\circ} 1$, mars 1926, p. 24-33. Sur le séjour à Paris d'Umehara, voir Fujihara 2008 : 456-458, $2011: 85-88$; Nanta 2012 : 97.

58. Morimoto Rokuji, "L'âge du bronze au Japon et l'expansion de la civilisation des Han vers l'est " (article rédigé en japonais à Paris en 1931 et traduit par Elisséev), Revue des Arts asiatiques. Annales du musée Guimet, t. VIII, n² 2, 1934, p. 65-76. 


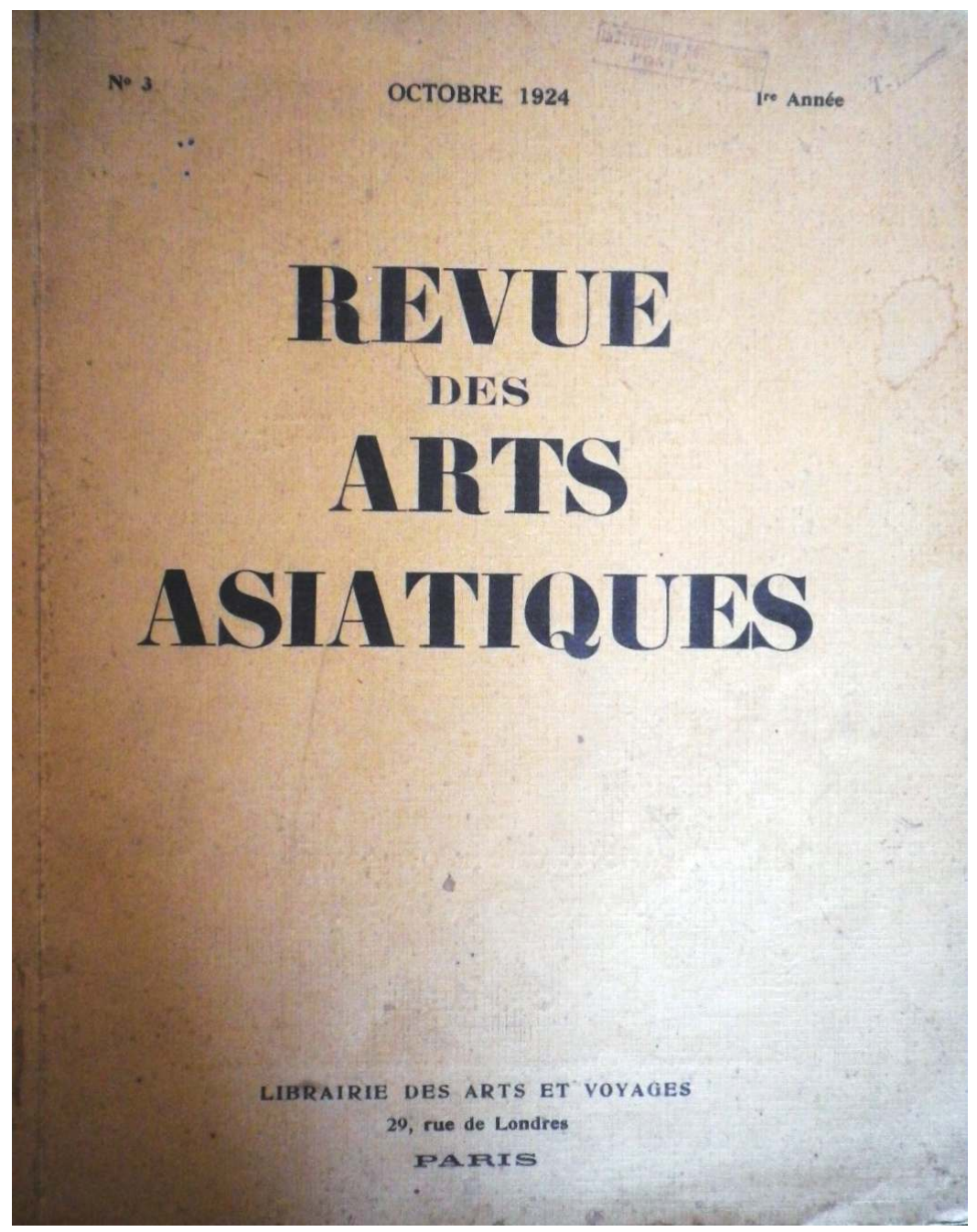

Fig. 14

Revue des Arts Asiatiques,

$\mathrm{n}^{\circ} 3$, octobre 1924. 
ceux du philologue Shinmura Izuru 新村出, sur l'introduction de la peinture occidentale au Japon à la fin du $\mathrm{XvI}^{\mathrm{e}}$ siècle $^{59}$. Il contribua ainsi au dépassement de l'amateurisme en matière d'histoire de l'art japonais (Frank 1973 : 266-267).

Japon et Extrême-Orient et la Revue des Arts asiatiques, deux périodiques nés en 1923 et 1924, sont emblématiques d'une nouvelle étape de la connaissance du Japon en France, marquée par l'évolution d'un orientalisme de cabinet vers des recherches de terrain et des échanges entre spécialistes des deux pays, insérés dans les milieux académiques respectifs. La première revue, publiée à la veille de la création de la Maison franco-japonaise, fut un périodique unique en son genre, qui allia à la fois l'information de première main sur l'actualité politico-diplomatique et culturelle japonaises, des essais à dimension historique et la présentation de chefs-d'œuvre de la littérature contemporaine. Elle compta parmi ses collaborateurs plusieurs figures majeures des études japonaises, qui joueront un rôle essentiel dans le développement de cette discipline en France et aux États-Unis.

La publication de ces deux revues est aussi révélatrice d'un tournant dans la perception du Japon en France dans les années 1920. Après la Première Guerre mondiale, le "japonisme " artistique et littéraire, qui avait été si vivant tout au long du dernier tiers du XIX ${ }^{\mathrm{e}}$ siècle, s'essouffle, et les grandes collections d'art japonais réunies à Paris sont pour la plupart dispersées en vente publique. Parallèlement, une génération de jeunes chercheurs japonisants émerge, même s'il ne s'agit encore que de quelques personnalités. La " japonologie ", terme qui fait son apparition à cette époque, commence à se former comme une discipline à part entière, bien qu' elle reste, et pour longtemps encore, marginale dans l'université française. Cette période inaugure ce que Jean-Jacques Origas a défini comme la troisième grande étape des études japonaises en France, après la "préhistoire » et la période des pionniers de la seconde moitié du XIX siècle (Origas 1985 : 84-88). Cette étape est marquée par la création d'institutions nouvelles qui seront

59. Izuru Shimmura, "L'introduction de la peinture occidentale au Japon " (article tiré de Nanban kōki 南蛮廣記, Tokyo, Iwanami shoten, 1925), Revue des Arts asiatiques, $I^{\mathrm{e}}$ année, $\mathrm{n}^{\circ}$ 4, septembre 1927, p. 195-203. Elisséev avait fait la connaissance de Shinmura Izuru (1876-1967), linguiste, philologue et spécialiste de la période chrétienne au Japon, lors de ses études à l'université de Berlin en 1907 et c'est ce dernier qui l'avait aidé à entrer ensuite à l'université impériale de Tokyo (Reischauer 1957 : 8-9). 
des foyers de collaboration entre la France et le Japon (la Maison francojaponaise en 1924, la Maison du Japon à Paris en 1929, l'Institut d'études japonaises de l'université de Paris ${ }^{60}$ en 1934), de chaires d'enseignement (pour les arts de l'Extrême-Orient à l'École au Louvre en 1925, dont l'art japonais à partir de 1927 sous la responsabilité d'Elisséev ${ }^{61}$, pour l'histoire des " religions du Japon ${ }^{62}$ " à la $\mathrm{V}^{\mathrm{e}}$ section de l'École pratique des hautes études en 1932), et par un intérêt grandissant pour le Japon contemporain, dans ses dimensions littéraires et artistiques, mais aussi politiques et sociales, qui apparait nettement au travers des pages de l'éphémère revue Japon et Extrême-Orient.

60. Cet institut, fondé à l'initiative de l'ancien ministre de l'Instruction publique André Honnorat, créateur de la Cité internationale universitaire de Paris, grâce à une donation de la société Mitsui gōmei kaisha, et qui fut installé à la Maison du Japon (Fondation Satsuma), avait pour objet " de favoriser tout enseignement pouvant contribuer à faire connaître en France, le Japon, son histoire, ses institutions, sa littérature, son art, ainsi que la constitution de son sol, la variété de ses ressources et de ses aspects, la vie morale et intellectuelle de la population " (Coopération intellectuelle, n 37, Société des Nations, 1934, p. 317). Sylvain Lévi en fut son premier vice-président de 1934 à 1935.

61. La chaire de l'École du Louvre, créée en 1925 par Georges Salles, fut occupée par Elisséev à partir de l'année 1927-1928, puis par Haguenauer à partir de 1933, qui donna des cours sur l'archéologie du Japon (David $1981: 69$ ).

62. Cette chaire de "Religions du Japon " sera occupée par S. Elisséev, directeur d'études, qui avait commencé son enseignement sous la forme de " conférences temporaires » en 1930. C. Haguenauer le remplacera en 1932-1932 lors de son absence pour enseignement à Harvard. 


\section{Bibliographie}

\author{
AUROUSSEAU Léonard, 1925 \\ «Claude Eugène Maitre », Bulletin de \\ I'École française d'Extrême-Orient, XXV : \\ 599-624.
}

\section{BAZAUD Maryse, LANG Claudine,} MALICET Marianne, 1979

Catalogue de la bibliothèque de Paul Claudel, Annales littéraires de l'université de Besançon, 229, Paris, Les Belles Lettres.

\section{BEFEO, 1921a}

«L'École française d'Extrême-Orient depuis son origine jusqu'en 1920 : historique général », Bulletin de l'École française d'Extrême-Orient, XXI : 1-41.

\section{BEFEO, 1921b}

"Japon », Bulletin de l'École française d'Extrême-Orient, XXI : 389-397.

\section{BEILLEVAIRE Patrick, 1993}

Le Japon en langue française. Ouvrages et articles publiés de 1850 à 1945, publication de la Société française des études japonaises, Paris, Éditions Kimé.

\section{BEILLEVAIRE Patrick, 2012}

[éd. or. 2008]

Notices sur « ELISSEEF (ou ELISSEEV)

Serge », " MAITRE Claude-Eugène », «PERI Noël » in François POUILLON (dir.), Dictionnaire des orientalistes de langue française, Paris, Karthala : 376-377, 670-672, 792-793.

\section{BONNEAU Georges, 1938}

Bibliographie de la littérature japonaise contemporaine, coll. « Bulletin de la Maison franco-japonaise », Tokyo, IX (1-4).

\section{BONNEAU Georges, 1940}

Histoire de la littérature japonaise contemporaine (1868-1938), préface de KIKUCHI Kan, Paris, Payot.

\section{BOUCHEZ Daniel, 1983}

«Un défricheur méconnu des études extrême-orientales : Maurice Courant (1865-1935) ", Journal Asiatique, CCLXXI : 43-150.

\section{CLAUDEL Paul, 1991 [1925]}

Supplément aux œuvres complètes, t. II, Lausanne, éditions L'Âge d'Homme :

125. Reprise de «Interview par Frédéric Lefèvre sur le Nô ", Les Nouvelles Littéraires, 18 avril 1925, republié dans Frédéric LEFÈVRE, Une heure avec..., Paris, NRF, 1925 : 151.

\section{COUCHOUD Paul-Louis, 1916}

"Les épigrammes lyriques du Japon », Sages et poètes d'Asie, Paris, CalmannLévy : 51-137.

\section{DAVID Madeleine Paule, 1976}

« Serge Elisseeff (1889-1975) », Arts

Asiatiques, 32 : 287-288.

DAVID Madeleine, 1981

"Les études d'art et d'archéologie du Japon ", actes du colloque Le Japon vu 
depuis la France. Les études japonaises en France, Tokyo, Publications de la Maison franco-japonaise : 67-76.

\section{DEMIÉVILLE Paul, 1937}

« L'Extrême-Orient dans l'œuvre de Sylvain Lévi », Bulletin de la Maison franco-japonaise, VIII (2-4) : 50-62.

\section{ELISSÉEV Serge (Erisēefu エリセーエフ),} 1921 [1976]

Sekiro no hitojichi nikki 赤露の人質日記 (Journal d'un otage de la Russie rouge), Osaka, Asahi shinbunsha 朝日新聞社， octobre 1921. [Réédition en 1976, avec un commentaire de KURATA Yasuo 倉田 保雄, Tokyo, Chūō kōronsha 中央公論社， coll. « Chūō bunko » 中央文庫].

\section{ELISSÉEV Serge, 1923}

La peinture contemporaine au Japon [en japonais sur la couverture : 英利世夫著 現代日本繪畫小史 Erisefu-cho Gendai Nihon kaiga shōshi], Paris, Éditions de Boccard.

\section{ELISSÉEV Serge, 1924}

Neuf nouvelles japonaises. Extrait de "Japon et Extrême-Orient », traduites par Serge ELISSÉEV, Paris, G. Van CEst.

\section{ELISSÉEV Serge, 1927a}

Le jardin des pivoines par Nagaï Kafû suivi de cinq récits d'écrivains japonais contemporains, traduction de Serge ELISSÉEV, Paris, Au Sans Pareil.

\section{ELISSÉEV Serge, 1927b}

« Un japonologue français: ClaudeEugène Maitre ", Artibus Asiae, 2 (1) : 49-57.
FRANK Bernard, 1973

"Cinquante ans d'orientalisme en France (1922-1972) ", Journal Asiatique, CCLXI : 255-295.

FRANK Bernard (éd.), 1980

Mélanges offerts à M. Charles Haguenauer en l'honneur de son quatre-vingtième anniversaire. Études japonaises, Paris, Collège de France, «Bibliothèque de I'Institut des hautes études japonaises », L'Asiathèque.

\section{FRANK Bernard, 1981}

"La japonologie, histoire et définition d'une approche ", actes du colloque Le Japon vu depuis la France. Les études japonaises en France, Tokyo, Publications de la Maison franco-japonaise : 6-20.

FROLOFF Nathalie, 2006

«Paulhan et les formes nouvelles d'écriture de La NRF : étude d'un cas, le haïku », in Jeanyves GUÉRIN (dir.), La Nouvelle Revue française de Jean Paulhan (1925-1940 et 1953-1968), Éditions Le Manuscrit : 65-92.

\section{FUJIHARA Sadao 藤原貞朗, 2008}

Orientarisuto no yūutsu. Shokuminchi shugi jidai no Furansu tōyō gakusha to Ankōru iseki no kōkogaku オリエンタリスト の憂鬱 —— 植民地主義時代のフランス 東洋学者とアンコール遺跡の考古学 (La mélancolie des orientalistes : les orientalistes français à l'époque coloniale et les recherches archéologiques sur les vestiges d'Angkor), Tokyo, Mekong めこん. 
FUJIHARA Sadao, 2011

«Orientarisuto no nichifutsu kōryū.

Taisenkan-ki oyobi senji-ka no nichifutsu kōryū no gyakusetsu »オリエンタリスト の日仏交流 一一 大戦間期および戦時下の 日仏交流の逆説 (Les échanges francojaponais entre orientalistes : le paradoxe des échanges franco-japonais entredeux-guerres et pendant la Seconde Guerre mondiale), Nichifutsu bunka 日 仏文化. Revue de collaboration culturelle franco-japonaise, 79 : 75-94.

\section{GÉRARD Auguste, 1919}

Ma mission au Japon (1907-1914). Avec un épilogue de 1914 à 1919 et quatre portraits, Paris, Librairie Plon.

\section{GOLOUBEW Victor, 1929}

«Deux amis du Japon: Claude Maitre et Noël Peri », Extrême-Asie. Revue indochinoise illustrée, numéro spécial sur le Japon, octobre, 40 : 719-726.

\section{GRAZIANI Jean-François, 2013}

« L'enseignement du français au Japon vu par Claudel durant son ambassade (1921-1927) : jugements, ambitions et réalisations ", Revue japonaise de didactique du français, septembre, 8 (2) : 20-32.

\section{HAGUENAUER Moïse Charles, 1924}

"Le conflit du Pacifique, la guerre civile en Chine et les tendances actuelles de la politique japonaise ", Japon et ExtrêmeOrient, novembre-décembre, $11-12: 370-384$.
HASEGAWA-SOCKEEL Masako

長谷川=ソケール・正子, 2012

«Gime bijutsukan to "Nihon bunka" » ギメ美術館と「日本文化」(Le musée Guimet et la « culture japonaise »), in WADA Keiko 和田桂子, MATSUZAKI Sekiko 松崎碩子, WADA Hirofumi 和田博文 (dir.), Mantetsu to nichifutsu bunka kōryū-shi « Furansu Japon » 満鉄と日仏文化交流誌『フランス・ジャポン』 (La Société des chemins de fer de Mandchourie du Sud et la revue de collaboration culturelle franco-japonaise France-Japon), Tokyo, Yumani shobō ゆまに書房 : 267-284.

\section{IWATANI Jūrō, 1999}

« La publication de la Revue française du Japon (1892-1897) : I'infructueuse tentative d'un juriste français, conseiller auprès du gouvernement japonais ", in Jean-Pierre BERTHON, Anne GOSSOT (dir.), Japon pluriel 3. Actes du troisième colloque de la Société française des études japonaises, Arles, Éditions Philippe Picquier : 45-52.

JEO

Japon et Extrême-Orient. Revue d'informations politiques, économiques, artistiques et littéraires, Paris, Edmond Bernard éditeur, douze numéros, dix fascicules, décembre 1923-décembre 1924.

KANEKO Mitsuko 金子美都子 \& SHIBATA Yoriko 柴田依子, 1999 Meiji Nihon no shi to sensō. Ajia no kenjin to shijin 明治日本の詩と戦争—アジア の賢人と詩人 (Poésie et guerre dans le 
Japon de Meiji. Sages et poètes d'Asie), Tokyo, Misuzu shobō みすず書房.

\section{KURATA Yasuo 倉田保雄, 2007}

Natsume Sōseki to japanorojï densetsu. "Nihon-gaku no chichi » wa monka no Roshia-jin Erisēefu 夏目漱石とジャパノロ ジー伝説—「日本学の父」は門下の ロシア人・エリセーエフ (Natsume Sōseki et la légende de la japonologie. Le « père de la japonologie » fut son disciple, le Russe Elisséev), Tokyo, Kindai bungeisha 近代文芸社.

MAITRE Claude Eugène, 1903 "Japon », Bulletin de l'École française d'Extrême-Orient, III (3) : 346-348.

\section{MAITRE Claude Eugène, 1904} "Japon », Bulletin de l'École française d'Extrême-Orient, IV (1-2) : 484-487.

\section{MAITRE Claude Eugène, 1922} « Noël Peri », Bulletin de l'École française d'Extrême-Orient, XXII : 404-417.

\section{MAITRE Claude, 1924}

«Un japonologue français Noël Peri ", Japon et Extrême-Orient, mars, 4 : 289-307. (Reprise avec quelques modifications de la notice nécrologique parue dans le Bulletin de l'École française d'Extrême-Orient, XXII (1922) : 404-417).

\section{MARQUET Christophe, 2002}

«Emmanuel Tronquois (1855-1918), un pionnier des études sur l'art japonais. Sa collection de peintures et de livres illustrés d'Edo et de Meiji », Ebisu. Études japonaises, automne-hiver, 29 : 115-165.
MAYAUX Catherine, 2010

«Claudel et la littérature japonaise ou Claudel en auteur japonais », in Didier ALEXANDRE, Pascale ALEXANDRE-BERGUES, Pascal LÉCROART (dir.), Paul Claudel et l'histoire littéraire, Presses universitaires de Franche-Comté, 2010.

MINAMI Asuka 南明日香, 2012 "Furansu-go ni hon.yaku sareta "Nihon bunka”»フランス語に翻訳された「日本文 化」(La «culture japonaise » traduite en langue française), in WADA Keiko 和田桂子, MATSUZAKI Sekiko 松崎碩子， WADA Hirofumi 和田博文 (dir.), Mantetsu to nichifutsu bunka kôryū-shi « Furansu Japon » 満鉄と日仏文化交流誌『フランス・ ジャポン』(La Société des chemins de fer de Mandchourie du Sud et la revue de collaboration culturelle franco-japonaise France-Japon), Tokyo, Yumani shobō ゆまに書房 : 300-316.

\section{NANTA Arnaud, 2012}

«The Japanese Colonial Historiography in Korea (1905-1945) », in Rosa CAROLI, Pierre-François SOUYRI (ed.), History at Stake in East Asia, Venezia, Libreria Editrice Cafoscarina, 2012 : 83-101.

\section{ORIGAS Jean-Jacques, 1985}

"Les études japonaises en France. Cinq étapes : notes sur I'histoire et l'état présent ", Japanese studies in Europe, Tokyo, The Japan Foundation, « Directory Series VII » : 79-102.

\section{PELLIOT Paul, 1925-1926}

"Claude Eugène Maitre », T'oung Pao, deuxième série, 24 (2/3) : 294-295. 
PERI Noël, 1921

Cinq Nô: drames lyriques japonais, Paris, Éditions Bossard, coll. « Les classiques de I'Orient ».

\section{PERI Noël, 1944}

Le Nô, préface de Sugiyama Naojirô, Tokyo, Maison franco-japonaise.

\section{RFJ, 2007}

Revue française du Japon,

Tokyo, Yūshōdō 雄松堂.

MURAKAMI Kazuhiro 村上一博，

«Fukkoku-ban kaidai : Futsubun

zasshi. Sōkan kara haikan made»

復刻版解題: 『仏文雑誌』——創刊から

廃刊まで (Commentaire du fac-similé :

Revue française du Japon. De sa

création à sa disparition).

REISCHAUER Edwin O., 1957

«Serge Elisséeff », Harvard Journal

of Asiatic Studies, juin, 20 (1-2) :

1-35.

\section{ROUSTAN Frédéric, 2008}

«Entre Tōyōgaku 東洋学 et Nan.yōgaku 南洋学. L'origine multiple des études vietnamiennes au Japon (1881-1951) », Ebisu. Études japonaises, printemps-été, 39 : 27-55.

\section{SHIBATA Yoriko 柴田依子, 2010}

Haiku to japonisumu. Kūshū to Nihon bunka kōryū 俳句のジャポニスム クーシューと日本文化交流

(Le japonisme dans le haïku. Couchoud et l'introduction de la culture japonaise), Tokyo, Kadokawa shoten 角川書店.
SHIRATORI Yoshihiko 白鳥義彦, 1999

«Meiji-ki no nichifutsu kankei to Futsubun zasshi » 明治期の日仏関係と 『佛文雑誌』(Les relations francojaponaises à l'époque de Meiji et la Revue française du Japon), Nichifutsu kyōiku gakkai nenpō 日仏教育学会年報/ Annales de la Société franco-japonaise des sciences de l'éducation, $28: 45-56$.

\section{TANIZAKI, 1925}

Puisque je l'aime (version française de S. Asada, H. Yokoyama et Charles Jacob), Paris, Éditions Émile-Paul frères. 